\title{
Francisco Bolsi
}

Historiador. Se graduó en la Universidad Nacional de Tucumán, obtuvo su maestría en la Universidad Pablo de Olavide, Andalucía, y su doctorado en la Universidad Nacional de Tucumán. Es becario posdoctoral del CONICET en el Instituto Superior de Ciencias Sociales (ISES). Es autor de: "Inmigración francesa, desarrollo agroindustrial azucarero y familia empresa. Tucumán, 18301920. El caso de la familia Nougués", Tiempos de América, Valencia, España, 2009, y "Familia, poder político y prácticas empresarias. Un estudio comparado de los casos de Felipe y Manuel Posse en el contexto del desarrollo agroindustrial azucarero tucumano, 1830-1900", Población y Sociedad, Tucumán, Argentina, 2009.

\section{Resumen}

El aporte fundamental de esta investigación fue analizar el proceso de revolución e independencia iniciado a partir de 1810 a la luz de las contribuciones solicitadas para el mantenimiento del ejército revolucionario y su incidencia en la elite tucumana, pero particularmente en la familia Posse. El iniciador de este clan familiar era un importante comerciante de origen peninsu- lar, poseedor de una de las mayores fortunas en la ciudad de San Miguel de Tucumán en 1813. Sus hijos, naturales de la región, también se dedicaron a las actividades mercantiles. En este sentido, en este trabajo se indagó sobre el efecto de las contribuciones solicitadas en el entorno familiar y las estrategias utilizadas por los Posse para atravesar el periodo revolucionario.

\section{Palabras clave:}

Empréstito, elite, familia, estrategias de reproducción social. 


\title{
Elite Families, Revolution, War. An Approach Based on an Analysis of the Posse Clan in Tucumán, Argentina, 1810-1830
}

\author{
Francisco Bolsi
}

Historian. A graduate of the Universidad Nacional de Tucumán, he obtained his MA from the Universidad Pablo de Olavide, Andalucía and his doctorate from the Universidad Nacional de Tucumán. Post-Doctoral grant-holder at the Instituto Superior de Ciencias Sociales (ISES). Author of: "Inmigración francesa, desarrollo agroindustrial azucarero y familia empresa. Tucumán, 18301920. El caso de la familia Nougués", Tiempos de América, Valencia, Spain, 2009, and "Familia, poder político y prácticas empresarias. Un estudio comparado de los casos de Felipe y Manuel Posse en el contexto del desarrollo agroindustrial azucarero tucumano, 1830-1900", Población y Sociedad, Tucumán, Argentina, 2009.

\begin{abstract}
The main contribution of this research was to analyze the process of revolution and independence begun in 1810 in light of the contributions requested to maintain the revolutionary army and its influence on the Tucumán elite, particularly the Posse family. The initiator of this family clan was a successful merchant

largest fortunes in the city of San Miguel de Tucumán in 1813. His sons, who were born in the region, were also in commerce. In this respect, this article explores the effect of the contributions requested in the family circle and the strategies used by the Posse to survive the revolutionary period.
\end{abstract} of Spanish origin, who possessed one of the

Key words:

Loans, elite, family, social reproduction strategies.

Final submission:

October 2008
Acceptance:

March 2009 


\title{
Familias de la elite, revolución y guerra. Una aproximación a partir del análisis del clan Posse en Tucumán, Argentina, 1810-1830
}

\author{
Francisco Bolsi
}

\section{INTRODUCCIÓN}

L

a historia de familia en Argentina evolucionó en los últimos quince años de una forma significativa y los trabajos realizados respondieron a diversas problemáticas relacionadas con ciertos procesos históricos específicos -revolución e independencia, confederación rosista, organización del Estado-nación, etc.-, que generaron el interés de los historiadores. ${ }^{1}$

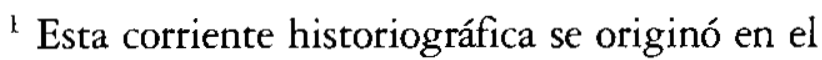
continente europeo, más precisamente en Inglaterra y Francia, a principios de la década de 1970 con el propósito de responder problemáticas que no habían sido respondidas hasta ese momento. En el caso inglés, los descubrimientos del Grupo de Cambridge, y en particular de Peter Laslett -quien propuso como herramienta metodológica construir una tipología para aproximarse a las fuentes sociodemográficas- de acuerdo con las diferentes clases de organización familiar generó una revolución historiográfica en el contexto de Inglaterra. Al respecto del caso francés, la escuela de los Annales suscitó a partir de 1920 una intensa revolución historiográfica que se apartó de los esquemas tradicionales del discurso histórico. En 1972, luego de que Braudel abandonó la dirección de la revista, surgió la denominada "tercera generación". Este grupo -en reacción a la férrea orientación impuesta por Braudel-, reorientó los paradigmas de análisis hacia el estudio de la historia cultural, las
El análisis de estos hechos identificó la lógica de las relaciones de parentesco, los vínculos extrafamiliares y el papel desempeñado por los diversos clanes familiares que participaron de dichos procesos; sus intereses económicos y las prácticas políticas de ese periodo. En el caso tucumano, la producción historiográfica aumentó en la última década del siglo Xx de manera

mentalidades, la política y lo narrativo. Sin embargo, fue Philippe Ariès, un hombre de la generación de Braudel, quien se interesó por la historia de las mentalidades. En Laslett, "Introducción" 1972, y Burke, Revolución, 1994. Poco tiempo después las sugerentes interpretaciones que realizaron Brading, Kicza y Socolow -de los diferentes procesos en el territorio dependiente de la metrópoli española- quienes analizaron la administración colonial y la inserción de diferentes clanes familiares en determinados espacios de poder entre fines del siglo XVIII y principios de la centuria siguiente, descubrieron diversos matices en la evolución política y las relaciones de parentesco de acuerdo con las regiones que analizaron. En Brading, Mineros, 1975; Kicza, Empresarios, 1986, y Socolow, Mercaderes, 1991. Un sugerente aporte para entender la conformación de las familias de la elite en la larga duración fue efectuado por Diana Balmori. Balmori, Voss y Wortman, Alianzas, 1990. La producción historiográfica en Argentina es sumamente amplia y a continuación sólo citamos algunos autores: Moutoukias, "Familia", 2000; Moreno, Historia, 2004; Hora, Terratenientes, 2002, y Bragoni, Hijos, 1999. 
considerable y los aportes realizados por diversos investigadores del medio local echaron luz sobre las problemáticas que no fueron contempladas por la historiografía tradicional. $^{2}$

En los albores del nuevo siglo, una temática recurrentemente debatida en diversas reuniones académicas giró en torno a los procesos de independencia y las consecuencias que generó la guerra en las distintas jurisdicciones del territorio colonial en donde se gestaron estos movimientos insurgentes. ${ }^{3}$ Esta problemática se encuentra estrechamente ligada al caso tucumano debido a que el territorio de la intendencia de Salta del Tucumán se transformó -en el transcurso del proceso revolucionario- en un espacio en donde dirimieron sus fuerzas las huestes patriotas y realistas. ${ }^{4}$ Asimismo, el triunfo del ejército del norte en la batalla de Tucumán (1812) frenó el avance realista y marcó el inició de

${ }^{2}$ Para el caso tucumano véanse Leoni, Tucumán, 2008; Bascary, "Poder", 1994, y Familia, 1999; López, "Redes", 2004; Iramain, "Proceso", 2005, y Herrera, "Redes", 2007.

${ }^{3}$ El interés por esta problemática esta directamente relacionado con la necesidad de revisar las perspectivas de análisis de cara al bicentenario de estos procesos revolucionarios en América Latina.

${ }^{4}$ Un elemento insoslayable del proceso revolucionario es el tema de la guerra. En este sentido, la producción historiográfica acerca de esta problemática da cuenta del peso económico que generó el conflicto en los territorios que fueron epicentro del mismo así como también el papel desempeñado por sus zonas de influencia. La producción historiográfica en el contexto latinoamericano es sumamente amplia, sin embargo, en este trabajo sólo citaremos las investigaciones realizadas para el contexto del noroeste argentino. Leoni, "Empréstito", 1973, pp. 165-177; Mata, "Costo", 1999; Gil, "Guerras", 2004, pp. 9-36; Schmit, Ruina, 2004, y Leoni, Tucumán, 2008. una serie de victorias que alejaron de la geografía tucumana el enfrentamiento armado.

El propósito de esta investigación es estudiar en un periodo específico (18101830) las repercusiones del proceso revolucionario en la jurisdicción de Tucumán: el análisis de las contribuciones solicitadas para la guerra y el entorno familiar de Manuel Posse -inmigrante peninsular de la oleada borbónica y prestigioso comerciante del medio local-, y de su familia.

Por este motivo, esta investigación girará en torno a dos ejes específicos de análisis: los empréstitos, por un lado, y la red parental de los Posse, por otro. ${ }^{6}$ El primero se plantea como una fuente pertinente para indagar las particularidades de uno de los mecanismos de coacción económica que implementaron las autoridades del Cabildo de la ciudad de San Miguel de Tucumán, para el mantenimiento de la causa revolucionaria -sobre todo del ejér-

${ }^{5}$ En esta investigación se utilizarán en forma indistinta los términos contribución o empréstito para designar el monetario que era entregado por los comerciantes de acuerdo con las distintas solicitudes efectuadas por las autoridades locales y de Buenos Aires. Asimismo, en algunas ocasiones estas contribuciones eran devueltas -restitución de empréstitosaunque esta práctica - de acuerdo con lo analizado- no era frecuente. Para el caso tucumano, esta temática fue tratada en forma general por López e Iramain. López, "Familias", 2004, e Iramain, "Proceso", 2005, pp. 85-162.

${ }^{6}$ En las dos décadas que se analizan en esta investigación, todos los empréstitos solicitados fueron forzosos. Las autoridades obligaban a los vecinos de la ciudad a contribuir, de lo contrario, la fuerza pública los haría cumplir con estas aportaciones. Hacia finales del decenio de 1810, estas contribuciones fueron cada vez más recurrentes y la presión ejercida fue mayor. 
cito- y las incidencias de las mismas en el patrimonio del clan familiar seleccionado. Esta premisa se sustenta en el hecho de que el peso de las contribuciones en la ciudad recayó en los comerciantes, pero sobre todo en el sector de españoles peninsulares (como Manuel Posse) quienes poseían las mayores fortunas. ${ }^{7}$

El estudio del entretejido parental de los Posse no se encuentra disociado del tema de las contribuciones. Las familias que integraron la red de parentesco se dedicaban a las actividades comerciales, por lo que tributaron de manera frecuente ante las necesidades de las autoridades revolucionarias. Asimismo, en ciertas ocasiones, en los empréstitos se encuentra registrado el monto tributado y el capital que poseía cada comerciante. Estos datos aportados por las fuentes resultaron de utilidad al momento de reconstruir el entretejido parental debido a que las familias que se unieron al clan Posse poseían cierto capital económico.

Manuel Posse era un comerciante peninsular de la corriente migratoria borbónica de fines del siglo XVIII. Previamente a su establecimiento en la ciudad de San Miguel de Tucumán realizó diversas transacciones comerciales en Buenos Aires y la región de Cuyo. En 1779 se radicó de manera definitiva en el territorio tucumano y poco después se destacaba como uno de los comerciantes más dinámicos de la ciudad. En 1783 contrajo matrimonio con Águeda Tejerina y Domínguez, integrante de una de las familias más prestigiosas del medio local, hecho que le permitió desem-

${ }^{7}$ Tanto Manuel Posse como sus hijos se dedicaron a las actividades comerciales, por lo que debieron pagar las contribuciones que impusieron las autoridades revolucionarias. peñar diversas funciones en el Cabildo de la ciudad. ${ }^{8} \mathrm{~A}$ fines del periodo colonial se destacó como uno de los comerciantes más importante del medio local debido al volumen de sus transacciones mercantiles que lo vinculaban con el espacio peruano y el puerto de Buenos Aires. ${ }^{9}$ El éxito económico de Posse estuvo directamente relacionado con el estrecho vínculo que mantenía con su hermano Gerardo -que se estableció en Buenos Aires- y fue el responsable de consolidar los contactos comerciales en esa ciudad y de importar los efectos de Castilla desde la península ibérica, para luego reenviarlos a Tucumán, donde eran nuevamente redistribuidos. ${ }^{10}$

8 "el ascenso de los comerciantes como miembros de la elite se verificó como resultado de su posesión de riquezas provenientes de su actividad mercantil y el acceso a los cargos capitulares, aunque fundamentalmente, esto pudo ser posible merced al entroncamiento que realizaron con familias tradicionales ya encumbradas mediante matrimonios ventajosos. Su ingreso a la ciudad y su reclutamiento como integrantes de la elite complejiza la conformación de la sociedad local." Marchionni, "Elite", 1999, p. 181.

9 "Es entre 1744 y 1778 que se va a reafirmar definitivamente el papel de Buenos Aires como mercado, polo de arrastre y centro de distribución para un vasto conjunto regional. Es decir, que la creación del virreinato del Río de la Plata en 1776, con capital en Buenos Aires y todas las medidas que lo acompañaron, fueron más que el origen, la confirmación legal de una realidad que ya empezaba a existir y que por supuesto fue así acentuada al máximo. Desde ese momento los mercaderes de Buenos Aires van a dominar indiscutiblemente sobre toda una vasta área que abarcaba desde Paraguay hasta Chile, desde Buenos Aires hasta el Alto Perú y aún un poco más allá." Gelman, Mercanchifle, 1996, p. 19.

${ }^{10}$ Se reconstruyó la red comercial de Manuel Posse gracias a los datos aportados por el trabajo de Cristina López referido a Tucumán. López, "Comercio", 1994. 
Durante el transcurso del proceso revolucionario, las nuevas autoridades del Cabildo impusieron una serie de empréstitos -no sólo a él sino también al resto de los comerciantes tucumanos-destinados al mantenimiento del ejército de Perú, que a partir del triunfo de la batalla de Tucumán de 1812 se acantonó en la ciudad hasta $1819 .{ }^{11}$ Posse fue sospechado de ayudar al ejército realista, por lo que le fueron embargados todos sus bienes y ante la presión de las autoridades revolucionarias se radicó en Córdoba entre 1811 y $1813 .^{12}$ En este último año se realizó un censo en la ciudad que estableció un capital existente -sobre todo los recursos materiales de la elite tucumana- de 320000 pesos, participando Posse con 60000 , hecho que lo transformaba en el comerciante más acaudalado de la ciudad. ${ }^{13}$ Asimismo, en el año 1815 solicitó la devolución de un empréstito a las autoridades del Cabildo, quienes reaccionaron negativamente a esta demanda y catalogaron a Posse como enemigo de la causa revolucionaria y falto de patriotismo.

Sus descendientes - naturales de la ciudad- participaron activamente del pro-

${ }^{11}$ Los hijos de Posse no eran considerados peninsulares sino naturales de la región por haber nacido en la ciudad de San Miguel de Tucumán. Asimismo, sus contribuciones fueron menores que las de su padre debido a que sus fortunas personales no eran muy significativas en el transcurso del periodo revolucionario.

${ }^{12}$ Este accionar por parte de Posse provocó un embargo por parte de las autoridades de Cabildo de todos sus bienes. En 1813, gracias a la venia del general Manuel Belgrano -jefe del ejército expedicionario del norte- regresó a la ciudad y le fue devuelto todo su patrimonio. Posse, Posse, 1996, p. 20.

${ }^{13}$ Archivo Histórico de Tucumán (en adelante AHT), sección Administrativa, 1813, f. 280. ceso revolucionario, integraron las filas del ejército patriota y contribuyeron en varias de las ocasiones solicitadas. ${ }^{14}$ Del mismo modo, su inserción como funcionarios públicos fue paulatina y poco a poco obtuvieron protagonismo en el Cabildo de la ciudad. Los enlaces matrimoniales que llevaron a cabo - con familias de la elite local vinculadas con las actividades comerciales-, consolidaron su prestigio social y económico en el medio tucumano.

Por este motivo, historiar a los Posse se transforma en un instrumento idóneo para indagar las implicaciones del estallido revolucionario en la elite tucumana y cómo afectó este proceso al clan familiar, que hasta 1810 reflejaba un comportamiento sumamente coordinado.

En este sentido, cabe preguntarse lo siguiente: ¿las contribuciones solicitadas por el Cabildo de la ciudad para el sostenimiento del movimiento revolucionario afectaron la posición económica de Manuel Posse -reconocido comerciante del medio local-y de sus hijos, quienes comenzaban sus actividades comerciales en la plaza tucumana? ¿Los empréstitos requeridos por las autoridades del Cabildo se orientaron hacia algún sector específico de la sociedad tucumana? En todo caso, ¿qué función cumplieron -en este contexto sumamente conflictivo- las uniones matrimoniales efectuadas por los Posse con familias que integraban la elite local? ¿Las estrategias de reproducción social implementadas sólo se destinaron a asegurar la continuidad del clan familiar en el contexto local o, por el contrario, cumplieron

${ }^{14}$ En el ejército participó Simón Posse, quien se alistó en el Regimiento de Caballería y un año después lo hizo Luis que integró la Primera Compañía de Comerciantes. Ibid., 1810, fs. 33-44, y 1811, fs. 13-14. 
alguna función específica? Asimismo, ¿las familias que se incorporaron al entretejido parental de los Posse se desenvolvían en algún ámbito específico - Cabildo, ejército, etc.-, lo que permitiría efectuar una relación directa entre prácticas matrimoniales y espacios de poder?

Sobre la base de lo expuesto y con la finalidad de responder a las interrogantes arriba planteadas, este trabajo se organizó con el análisis de diversos fondos documentales. En el Archivo Histórico de Tucumán (AHT) se indagó la sección Administrativa en la que se analizaron las sucesivas contribuciones y empréstitos solicitados para mantener al ejército y su incidencia en los actores sociales que se estudian en esta investigación. Se estudió la sección Judicial Civil con la finalidad de analizar los testamentos y los conflictos que los mismos generaron al interior de la familia Posse. Se analizaron las actas del Cabildo y de la Sala de Representantes que permitieron observar la participación de los Posse en este ámbito específico. En este mismo lugar, se examinó el boletín genealógico con la finalidad de reconstruir los entretejidos parentales y establecer las estrategias matrimoniales.

\section{UN INMIGRANTE PENINSULAR}

EN TUCUMÁN A FINES DEL SIGLO XVIII. ESTRATEGIAS ECONÓMICAS E INSERCIÓN SOCIAL

Manuel Posse, el fundador del clan en Tucumán, era hijo de Domingo Antonio Posse y de Ana María Blanco de Martínez. ${ }^{15}$ La pareja, además de Manuel, con-

${ }^{15}$ Manuel Posse y Blanco nació en la villa de Camariñas (la Coruña), el 7 de octubre de 1753. Hijo cibió a otro hijo llamado Gerardo que junto al primero emigró hacia territorio americano en la segunda mitad del siglo XVIII. El padre de estos jóvenes, según el catastro del marqués de Ensenada levantado en 1753 , poseía un galeón para el comercio de cabotaje en los puertos portugueses y gallegos. Con esta propiedad, además de casas y cultivos, fue señalado como uno de los hombres de fortuna de la región en donde habitaba. ${ }^{16}$ Manuel, desde joven, estuvo involucrado junto a su hermano Gerardo en las actividades desarrolladas por su padre. En este sentido, la situación favorable de los comerciantes gallegos, luego de la aprobación del Tratado de Libre Comercio en 1774, y las oportunidades de crecimiento económico que ofrecía el territorio americano, motivaron el desarraigo de Posse de la Coruña. ${ }^{17} \mathrm{Al}$ igual que otros connacionales, los hermanos Posse emigraron hacia América con el propósito de acrecentar sus fortunas personales mediante el desarrollo de diversas actividades comerciales. ${ }^{18}$

de don Domingo Antonio Posse y de doña María Blanco y Martínez. Archivo Parroquial de Camariñas (en adelante APC), Libro de bautismos, núm. 1, f. 119.

${ }^{16}$ Archivo del Reino de Galicia (en adelante ARG), "Catastro del marqués de la Ensenada"; San Jorge de Buria y villa de Camariñas (Ayuntamiento de Vimianzo), año 1753, Real Legos, 510/12.

${ }_{17}$ Posse, Posse, 1996, p. 22.

${ }^{18}$ Las investigaciones al respecto del impacto de la inmigración de la oleada borbónica son abundantes y coinciden en que esta nueva elite que se radicó en América generó una transformación hacia el interior de las familias tradicionales que debieron fusionarse con estos nuevos sectores. Esta fusión de intereses no tuvo la misma repercusión para todas las familias del ámbito tucumano, debido a que algunos clanes se unieron con estos integrantes de la nueva "elite", mientras que otros mantuvieron la vigencia de 
En el siglo XVIII la situación económica de la ciudad de San Miguel de Tucumán era favorable debido a su ubicación como intermediaria en el eje Potosí-Buenos Aires. De acuerdo con López, la región del Tucumán seguía caracterizándose por su producción ganadera destinada a dos mercados: como ganado en pie que se transportaba hacia las provincias altoperuanas (especialmente a Tarija y Cinti) y como productos derivados (cueros, suelas, grasa, sebo) orientados a los mercados del Litoral. Complementaban la producción local otros bienes como los pellones, el arroz, las maderas, los muebles, las carretas, que se dirigían a la capital del virreinato y zonas aledañas. Desde Tucumán se enviaba el ganado, los pellones y los productos de reexportación (como la yerba y el azúcar) a los mercados del Alto Perú. A cambio de sebo, grasa y quesos se obtenía el metálico y productos manufacturados como los textiles, los sombreros y las mantas. Hacia el Litoral y el puerto de Buenos Aires se destinaban los cueros curtidos, el arroz, las maderas y las carretas. En la ciudad portuaria los comerciantes tucumanos adquirían los efectos de Castilla, la yerba, el azúcar y las manufacturas que no se producían en la jurisdicción y saldaban las cuentas con plata adquirida en los mercados altoperuanos o en la misma capital del virreinato. ${ }^{19}$

los lazos tradicionales. En este sentido, el éxito de unas familias y el fracaso de otras estuvo relacionado principalmente con las elecciones que llevaron a cabo. La bibliografía al respecto es abundante, pero en esta ocasión sólo citaremos aquellos trabajos que resultaron significativos para esta investigación. Para el caso tucumano, véanse Bascary, Familia, 1999. Para los casos de América Latina: Brading, Mineros, 1975.

${ }^{19}$ López, Dueños, 2003, p. 194.
Esta coyuntura económica favorable de la ciudad fue capitalizada por Posse, quien desde fines del siglo XVIII, concentró sus transacciones económicas hacia el Atlántico, más precisamente hacia Buenos Aires. ${ }^{20}$

Las gráficas 1 y 2 revelan los productos comercializados por el peninsular en dos periodos específicos: 1786-1798 y $1799-1810 .^{21}$

Estas gráficas revelan diversas cuestiones. Por una parte, el volumen de las exportaciones hacia la ciudad de Buenos Aires y, por otra, los productos comercializados con esa plaza. ${ }^{22}$ Sin embargo, una cuestión que subyace a simple vista es la fuerte presencia de las suelas como primer rubro exportable. Asimismo, el volumen de la producción de suelas indica el desarrollo de una incipiente manufactura en la jurisdicción de la intendencia de Salta de Tucumán, lo que se puede interpretar como el antecedente del auge de la curtiduría a partir de la década de 1830 .

${ }^{20}$ Los comerciantes de Tucumán se especializaron en diversos rubros. En este sentido, la especialización productiva de Manuel Posse se reorientó en gran medida hacia Buenos Aires.

${ }^{21}$ Los gráficos confeccionados sólo cumplen la función de ilustrar los productos comercializados por Posse, pero desde ningún punto de vista intentan realizar una interpretación de la evolución y complejidad de las transacciones comerciales de la ciudad de San Miguel de Tucumán entre fines del siglo XVIII y principios del XIX. Para ahondar en esta temática, véase López de Albornoz, "Tiempo", 2002.

${ }^{22}$ El circuito mercantil sur -provincias del litoral y Buenos Aires- era el preponderante, aun así no el único. En este sentido, la producción historiográfica hace referencia al circuito norte, vinculado con el Alto Perú, el oeste con Santiago del Estero y Córdoba y el este con la región norte de la capitanía de Chile. Nicolini, Flujos, 1994; "Comercio", 1994, pp. 47-79, y "Circuitos”, 1992, pp. 63-95. 


\section{SECUENCIA}

Gráfica 1. Productos exportados por Posse hacia Buenos Aires entre 1786-1797

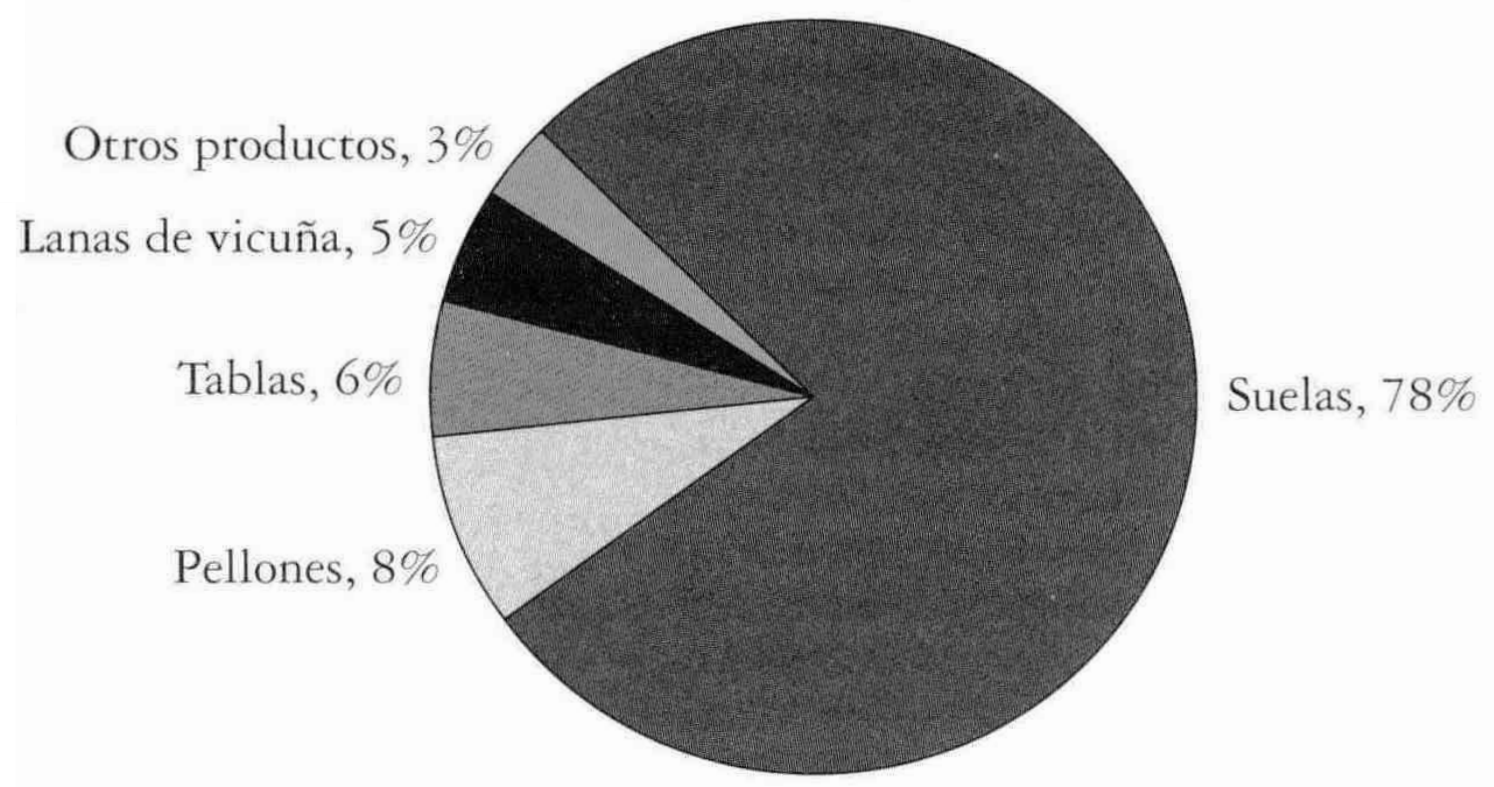

Fuente: López, "Comercio", 1994, pp. 20-23.

Gráfica 2. Productos exportados por Posse hacia Buenos Aires entre 1798-1810

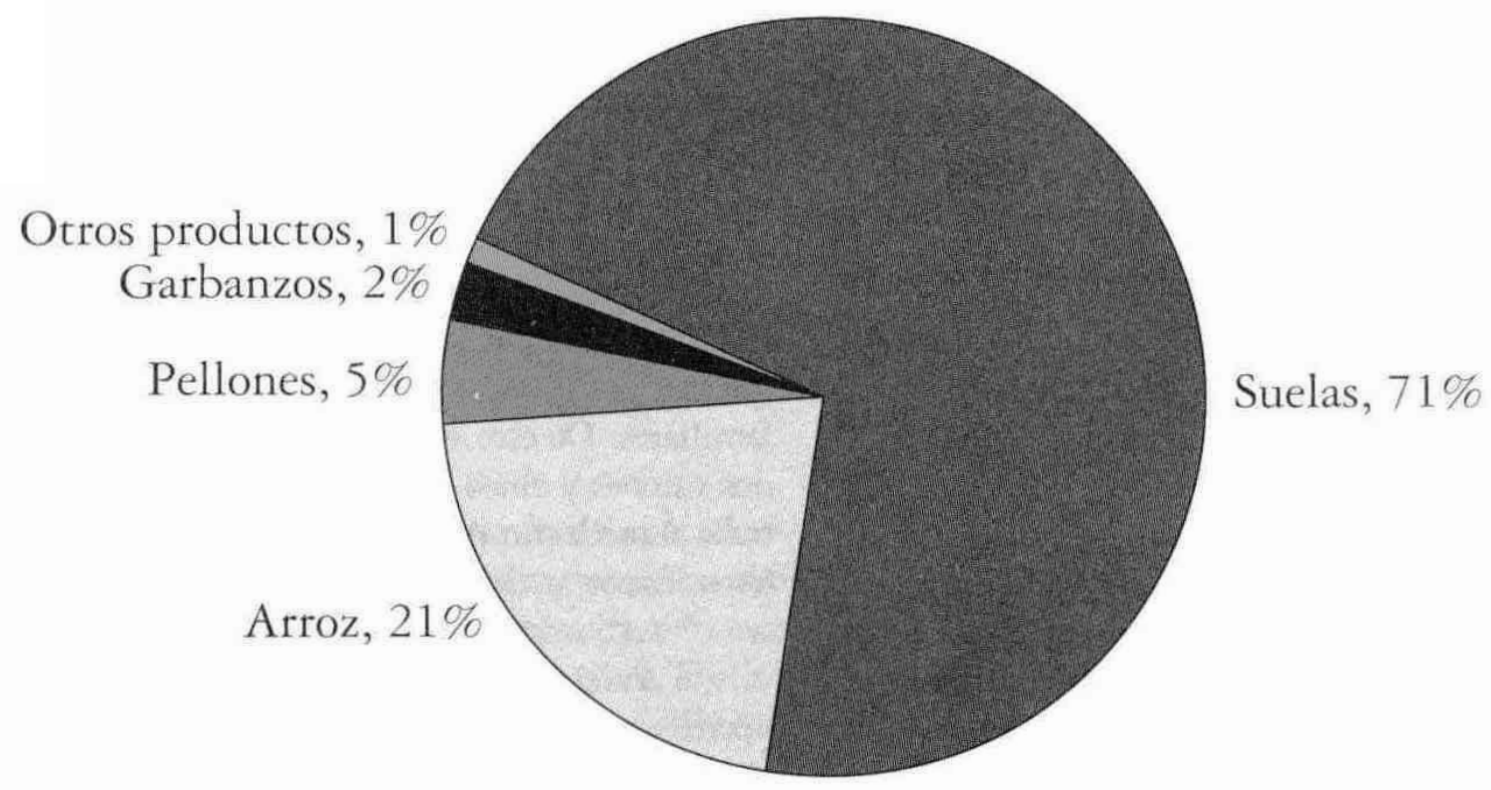

Fuente: López, “Comercio”, 1994, pp. 20-23. 
Respecto a los otros rubros que exportó Posse variaron de un periodo a otro y representan un porcentaje mucho menor que las suelas. En todo caso, una cuestión que se infiere de estos cuadros, es la demanda sumamente heterogénea de productos del mercado consumidor de la región del Litoral y de la ciudad de Buenos Aires, hecho que provocó que los productores tucumanos se especializaran en la elaboración de ciertos productos como los quesos y los cueros.

Un dato que no es posible deducir de ninguno de los gráficos es quiénes eran los destinatarios de estos productos, interrogante que está directamente vinculado con la red comercial de Posse y los consignatarios que la integraban. En este sentido, las fuentes revelan que Gerardo Antonio Posse -hermano de Manuel- fue el destinatario de la mayor cantidad de suelas en el periodo 1788-1810 (véase gráfica 3). ${ }^{23}$ La implementación de esta estrategia comercial está vinculada con el estrecho lazo familiar que mantuvo con su hermano, quien no sólo recibía los productos enviados por Manuel, sino que también era el encargado de importar los efectos de Castilla desde la península ibérica y luego reenviarlos a Tucumán.

Respecto a su inserción en la sociedad, al momento de radicarse adquirió la casa de Simón Antonio Domínguez, comerciante de la ciudad, vecino "distinguido" y en varias ocasiones funcionario del Cabildo. ${ }^{24}$

${ }^{23} \mathrm{Si}$ se retoma el análisis de la gráfica se puede observar que el segundo destinatario era Tomás Insúa, -comerciante de la plaza porteña- quien se encontraba vinculado con la familia Posse desde el casamiento de su hija con Gerardo Posse.

${ }^{24}$ Centro de Estudios Genealógicos de Tucumán, Boletín, núm. 5, 2007.
En 1783 se casó con la sobrina de Domínguez -Águeda Tejerina y Domínguez-en la ciudad de San Miguel de Tucumán. ${ }^{25}$ Al momento de contraer matrimonio Posse contaba con una fortuna que rondaba los 14000 pesos, sin deuda alguna, mientras que su mujer recibió como dote la suma de 4814 pesos. ${ }^{26}$ Este enlace benefició a ambos cónyuges de diversas maneras. Por una parte, los Tejerina consolidaron su capital simbólico al unir en matrimonio a una de sus descendientes con un comerciante peninsular que integraba la nueva elite de fines del periodo colonial. ${ }^{27}$ Por otra, Manuel Posse,

25 Águeda Tejerina y Domínguez era descendiente de Fermín Tejerina y Barreda (arrendatario de la Sisa en 1764 y recusado como alcalde de segundo voto en 1767 y como gobernador de Armas en 1776) de profesión comerciante, y Teresa Domínguez era natural de San Miguel de Tucumán, hija legítima del general Diego Domínguez y Teresa Rodríguez. El padre de Águeda era hijo de Francisco Tejerina Barreda, quien desempeñó diversos cargos públicos (alcalde de la Santa Hermandad y regidor XXIV), 1785 (alcalde ordinario de primer voto y regidor XXIV), 1787 (regidor XXIV y diputado del ramo de Sisa), 1788 (administrador de Temporalidades) y Laurencia García, naturales de Sevilla. Los Tejerina eran una de las familias más prestigiosas del ámbito local, pertenecían al sector de españoles peninsulares, cuyas raíces estaban vinculadas con antiguos troncos coloniales. $\mathrm{La}$ unión de Francisco Tejerina y Teresa Domínguez (padres de Águeda) fusionó dos importantes clanes familiares. De este matrimonio nacieron siete hijos, dos varones y cinco mujeres, entre las que se encontraba Águeda. En Archivo de la Catedral de Tucumán (en adelante ACT), Matrimonios III, f. 3, p. 45.

${ }^{26}$ AHT, sección Protocolos, serie A, 1839, fs. 21-24.

27 Ávila identifica al padre de Fermín Tejerina -padre de Águeda- como un "prestigioso" comerciante de la ciudad. Sin embargo, al cotejar esta afirmación en las guías de comercio del AHT entre 1786 y 1810 se comprobó que en realidad las transacciones 
Gráfica 3. Suelas exportadas a diversos consignatarios entre 1788-1810

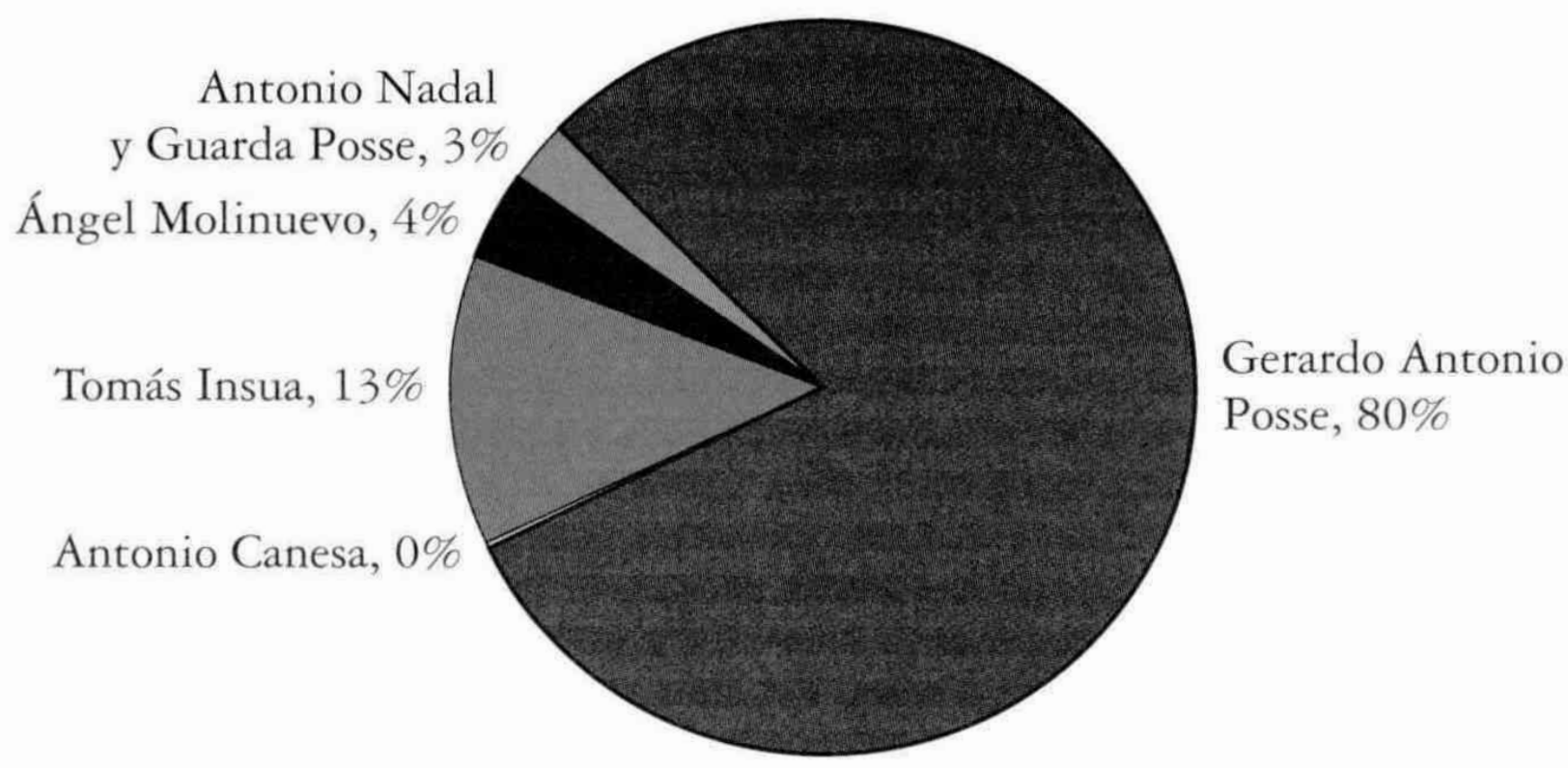

Fuente: López, “Comercio”, 1994, pp. 24-26.

a partir de su enlace matrimonial, se incorporó en forma definitiva como vecino de la ciudad, hecho que le permitió insertarse en el contexto político local. La dote que recibió su esposa como legítima herencia aumentó el patrimonio que ya poseía. Manuel y Águeda tuvieron una descendencia numerosa: seis varones (José Víctor, Vicente, Simón, Francisco, Luis y Felipe) y una hija (María del Rosario) quienes aseguraron la continuidad del linaje familiar en la ciudad de San Miguel de Tucumán. ${ }^{28}$

económicas no son representativas como para identificarlo como un comerciante significativo del medio local. En todo caso, el prestigio que le adjudica este autor esta más vinculado con el desempeño de Tejerina en la función pública debido a que ocupó diversos cargos, como se detalló en la nota 25.

${ }^{28}$ José Víctor (26 de agosto de $1785 / 24$ de mayo de 1852), Simón (1790), Vicente (4 de abril de $1796 /$
Asimismo, una característica de este clan familiar es el funcionamiento coordinado en el que tanto el padre como sus hijos se dedicaron a las actividades comerciales.

\section{LOS SUCESOS REVOLUCIONARIOS}

Y SU REPERCUSIÓN EN LA FAMILIA POSSE.

UNA APROXIMACIÓN A PARTIR DEL ANÁLISIS DE LAS CONTRIBUCIONES PARA LA GUERRA EN LAS DÉCADAS DE 1810 Y 1820

El proceso revolucionario, más allá de implicar la continuidad de algunas instituciones, normativas y actores coloniales,

09 de agosto de 1884), María del Rosario (1794), Luis (10 de abril de 1797), Felipe (30 de abril de 1806/30 de julio de 1878), Francisco Posse (se desconoce cualquier otro dato al respecto de su persona). 
generó la culminación de la participación de Manuel Posse como funcionario público. ${ }^{29}$ En años anteriores a los acontecimientos de 1810, el peninsular desempeñó diversas funciones en el Cabildo de la ciudad como regidor y en alguna ocasión como defensor de menores. ${ }^{30}$ No obstante, a partir del acta de adhesión a la Junta Provisoria de Buenos Aires -en la cual aparece como uno de los suscritos-, no volvió a participar en el Cabildo durante la década de $1810 .{ }^{31}$ Esta situación se agudizó más aún luego del decreto del director supremo de las Provincias Unidas del Río de la Plata, Antonio Posadas, quien sugiere a las autoridades locales que: "Se

29 "Se parte de la hipótesis de que los sucesos acaecidos a partir de 1810 , si bien configuran un hito fundamental en la vida política tucumana, no fracturaron la historia local en un antes radical y en un después igualmente terminante. Actores, sociedad, normas, usos, costumbres y prácticas están lejos de experimentar un quiebre político absoluto. El mundo social de la vida y las mismas exigencias de formación de un nuevo sistema político impidieron que se produjera una sustitución inmediata y radical. Aun cuando en el desarrollo del proceso llega un momento en que se reniega del pasado y el discurso plantea un corte definitivo de ese pasado, las prácticas, las normas y las leyes del viejo sistema siguen formando parte del soporte donde se asienta, en los primeros tiempos, la comunidad política local. Siguiendo esta línea de análisis se procura averiguar si algunas normas, prácticas y costumbres del pasado se resignifican en el marco de la revolución y tienden a la construcción de un nuevo y particular edificio político." García de Saltor, Construcción, 2003, p. 52.

${ }^{30}$ Posse se desempeñó como defensor de menores en 1787 , procurador de la ciudad en 1788 , alcalde de barrio en 1793, tesorero de bulas en 1801, y como alcalde ordinario de primer voto en 1804. Centro de Estudios Genealógicos de Tucumán, Boletín, núm. 5 , 2007, pp. 22, 25 y 28.

${ }^{31}$ Documentos, 1939-1940, vol. I, p. 41. debe seleccionar como candidatos elegibles para ocupar cargos en el Cabildo a los naturales de la provincia." ${ }^{32}$ Esta medida tenía el propósito de apartar paulatinamente a los peninsulares de los ámbitos de decisión política y administrativa.

Las autoridades locales, ante los escasos recursos en las arcas del Cabildo para solventar los gastos ocasionados por el ejército patriota, implementaron una serie de empréstitos forzosos a los vecinos de la ciudad. ${ }^{33}$ En esta ocasión, el interés de esta investigación radicó en las contribuciones que se efectuaron en la década de 1810 y 1820 debido a que las contribuciones son en metálico, hecho que brinda una imagen de cuánto aportó la familia Posse en el transcurso del periodo seleccionado. De acuerdo con Tío Vallejo:

El mantenimiento de los soldados y la preparación y apoyo de las expediciones obligaron a la ciudad a un enorme esfuerzo de adaptación a estas necesidades. Tuvo que proveer de alojamiento, alimento, atención sanitaria, vestuario y armas a los soldados. Se organizaron una fábrica de fusiles, una maestranza de artillería y varios hospitales militares. Cuando el gobierno "nacional" no proveía el dinero necesario para los sueldos, la provincia lo aportaba ya sea de sus cajas, mediante empréstitos que fueron cada vez

32 AHT, sección Administrativa, 1813, f. 400.

${ }^{33}$ Los empréstitos forzosos se destinaron al pertrecho de armamento, aprovisionamiento de vituallas y a la paga de los soldados. Las mismas permiten individualizar a quienes integraban las familias de mayor prestigio y capital monetario de la ciudad. Sin embargo, el pedido recurrente de dinero por parte de las autoridades recayó en un sector -los comerciantes- que por su actividad económica poseían innumerables recursos materiales. 
más frecuentes, o simplemente "debiendo" productos y servicios a los particulares. ${ }^{34}$

En este sentido, montos solicitados en las contribuciones variaron de acuerdo con los problemas generados por la guerra, lo que obligó a las autoridades a requerirlas con urgencia ante la premura de los acontecimientos. ${ }^{35}$ Los numerosos reclamos por los montos solicitados y la demora en las devoluciones del monetario contribuido, generaron ciertos reclamos por parte de los comerciantes, quienes no cuestionaban el mando político ni el desarrollo de la guerra, sino que su objetivo era recordarle a las autoridades la devolución de las numerosas contribuciones efectuadas. ${ }^{36}$ A partir de 1816 se aplicó el sistema de prorrateo que fijaba el monto de las contribuciones con base en las fortunas personales, tasadas por el diputado de Comercio. ${ }^{37}$ El cobro de estos fondos económicos, después del reemplazo de Bernabé

34 Tío, Antiguo, 2001, pp. 191-92.

${ }^{35}$ Se hace referencia a la naturaleza "diversa" de estas contribuciones porque en ocasiones se solicitó metálico y en otras ocasiones armas, vituallas para los soldados, caballos, mulas; es decir, todos los pertrechos necesarios para el ejército. Sin embargo, en esta ocasión sólo se indagarán los empréstitos monetarios debido a que el propósito de esta investigación es analizar su incidencia en el patrimonio de la familia Posse.

${ }^{36}$ De acuerdo con Leoni Pinto, el pedido recurrente de empréstitos sumado a la falta de garantías de la devolución del monetario contribuido generó cierta resistencia de los contribuyentes extraordinarios. El eje de los reclamos se centró en la paupérrima situación económica por la que atravesaban en el ámbito local. Leoni, Tucumán, 2008, p. 45.

${ }^{37}$ Los empréstitos forzosos variaron de acuerdo con el monto de las fortunas personales. Lizondo, Historia, 1948, p. 43.
Araóz por Feliciano de la Mota Botello, pasó a centralizarse en manos del jefe de ejército, Manuel Belgrano, lo que coincidió con un periodo de mayor rigidez en el cobro de los mismos. ${ }^{38}$

Los empréstitos solicitados afectaron a una amplia gama de contribuyentes -pulperos, tenderos, importantes estancieros y grandes comerciantes- del medio local. Sin embargo, el sector de españoles peninsulares era el que contaba con las mayores fortunas, hecho que generó que el peso del sostenimiento del ejército recayera en ellos. ${ }^{39}$

La biografía de los Posse hace referencia a la presunta oposición de Manuel con respecto a las exacciones económicas realizadas por las autoridades del Cabildo y su desencanto por el fortalecimiento del ideal revolucionario. ${ }^{40}$ Sin embargo, las afirmaciones vertidas por la tradición familiar no tienen ningún asidero en fuentes documentales, por lo que resultan infundadas.

Leoni Pinto se refiere a este mismo tema diciendo que "los posibles enemigos del sistema debían mostrar una actitud muy cauta [...] Más aún debieron dar muestras de ferviente patrio-

${ }^{38}$ Iramain, "Proceso", 2005, p. 127.

39) Algunos de los actores económicos a los que se hizo referencia eran: José Ignacio Garmendia (comerciante); José Velarde (comerciante); Lorenzo Domínguez (pulpero), quienes aparecen en el censo efectuado en 1813 con algunos de los mayores caudales existentes en la jurisdicción de San Miguel de Tucumán. AHT, sección Administrativa, 1813, f. 400 .

${ }^{40}$ El libro escrito por José María Posse, si bien hace referencia a fuentes documentales en el desarrollo de la historia familiar, en este tema específico de la "supuesta" oposición al movimiento revolucionario se basa sólo en la tradición oral, por lo que resulta poco sustentable esta versión. Posse, Posse, 1996, p. 24. 
tismo." ${ }^{41}$ Por este motivo, resulta poco probable que Posse socorriera al ejército realista sin ser sospechado de traidor a la causa revolucionaria, como se mencionó en la historia familiar.

En todo caso, los datos aportados por las fuentes familiares no permiten establecer la filiación ideológica de Manuel Posse con respecto al proceso revolucionario. Su comportamiento estuvo más relacionado con su intención de proteger su patrimonio de las diversas exacciones -reacción común entre todos los comerciantes-a las que fue sometido que a una oposición decidida al nuevo proyecto político que se gestó a partir de 1810 .

Asimismo, las fuentes revelan que en el transcurso de 1811 Posse no realizó ninguna transacción comercial en la plaza tucumana, pues no existen registros sobre su persona para este año. El pago de impuestos en concepto de la pulpería que poseía fue cancelado por un dependiente suyo, Manuel Vázquez. ${ }^{42}$ En este sentido, esta carencia de datos indicaría que Posse no se encontraba en San Miguel de Tucumán, lo que avalaría las versiones de la historia familiar referida a su residencia transitoria en la ciudad de Córdoba.

Sin embargo, la ausencia de Posse fue transitoria. En 1813 las autoridades del Cabildo llevaron a cabo un censo con la finalidad de establecer la cantidad de dinero existente en la ciudad. Los datos aportados revelan que, sobre un total de 320000 pesos, Posse tenía una fortuna estimada en 60000 pesos, hecho que lo transformaba en el comerciante más acau-

${ }^{41}$ Leoni, Tucumán, 2008, p. 37.

${ }^{42}$ En este sentido, esta carencia de datos indicaría que Posse no se encontraba en San Miguel de Tucumán. Documentos, 1939-1940, vol. I, p. 61. dalado de la ciudad. ${ }^{43}$ En todo caso, esta situación indicaría que el peninsular contaba con numerosos recursos materiales, por lo que su estadía en Córdoba no repercutió en su patrimonio.

Con respecto a esto, la tradición familiar afirma que a partir de este censo, Posse sufrió una serie de empréstitos forzosos que incidieron de manera significativa en su patrimonio. ${ }^{44}$ Estas versiones carecen de sustento por dos motivos esenciales. Por una parte, de los nueve empréstitos solicitados en el periodo estudiado, el peninsular contribuyó en cuatro ocasiones, a diferencia de otros individuos que tributaron en las nueve oportunidades en el decenio de 1810 (véase anexo, cuadro 1$).{ }^{45}$ Sin embargo, a pesar de ello, el dinero aportado ascendió a 3015 pesos, que fue una suma significativa si se tiene en cuenta que sólo tres personas contribuyeron con montos superiores en este periodo. En todo caso, de este listado de 18 individuos, $80 \%$ del capital fue apor-

${ }^{43}$ El propósito del censo fue establecer una estimación de los recursos materiales de los que disponían las familias más acaudaladas de la ciudad, entre las que se encontraba Posse. El segundo de esta lista era José Velarde con 15000 pesos. AHT, sección Administrativa, 1813, f. 351.

${ }^{44}$ Posse, Posse, 1996, p. 29.

45 "Tomando el caso de Pedro Cayetano Rodríguez, el único que estuvo presente en todos los listados registrados, aportó una cantidad de 5802 pesos, la mayor suma de todas. Pero este dato se relativiza si tenemos en cuenta que otros comerciantes, o tenderos o pulperos, contribuyeron en menor cantidad de oportunidades, aunque los montos son cercanos [...] Esto llevaría a pensar que el mayor grado de compromiso y participación no estaba dado por la recurrencia en los desembolsos, y poner mayor acento en las cantidades otorgadas." Iramain, "Proceso", 2005, p. 128. 
tado por el sector de comerciantes peninsulares, $17 \%$ por americanos y $3 \%$ por individuos de diversa nacionalidad (véase anexo, gráfica 1).

Por otra parte, en las fuentes analizadas para el periodo estudiado, no se observa la implementación de otras contribuciones -en el caso específico de Posse- con respecto al resto de los vecinos de la ciudad. ${ }^{46}$ Asimismo, si se analiza su testamento se puede comprobar que su patrimonio en 1839 -año en que falleció- era de 30887 pesos (véase anexo, cuadro 4). ${ }^{47}$ Sin embargo, esta merma tan significativa de su patrimonio -poseía en 1813 60000 pesos en recursos materiales- no revela, como se observará más adelante, que las contribuciones incidieron en la pérdida de la mitad de su patrimonio, sino que estuvo más vinculada con adelantos de herencia a sus descendientes.

En el caso de los descendientes de Manuel Posse, quienes eran considerados americanos, las fuentes analizadas ofrecen una información precisa de los montos tributados y la cantidad de veces que lo hicieron (véase anexo, cuadro 5). Sin embargo, lo que subyace es la participación de los hijos del peninsular desde dos perspectivas. Por una parte, su incorporación a las filas del ejército ${ }^{48} \mathrm{y}$, por otra, el pago

${ }^{46}$ Se interpreta como "nuevas contribuciones" a aquellos empréstitos que, de acuerdo con la historia familiar, le fueron solicitados a Posse en diversas ocasiones, además de los empréstitos oficiales.

${ }^{47} \mathrm{El}$ inventario de caja de Manuel, incluyendo todos los bienes, entre ellos la casa ocupada por su esposa, quintas y préstamos a particulares que no fueron cancelados, reunió la suma de 30887 pesos. AHT, sección Protocolos, serie A, año 1839, fs. 21-24v.

${ }^{48}$ Simón Posse en 1810 se alistó en el Regimiento de Caballería como voluntario, y un año después de las contribuciones solicitadas para el sostenimiento de la guerra, las cuales se analizarán a continuación.

\section{LOS EMPRÉSTITOS EN LA DÉCADA DE 1810}

El análisis específico de los empréstitos generó la diferenciación entre contribuciones en metálico y en especie -lo primordial eran las monturas, las mulas, los fusiles, etc. En todo caso, el propósito de este trabajo -como se mencionó previamente- fue indagar solamente las tributaciones que realizaron los Posse en metálico para el periodo estudiado. Esta decisión no desmerece las donaciones efectuadas por este clan familiar en especie, pero como se trata de una aproximación inicial a esta temática se eligió sólo un aspecto a analizar.

Asimismo, los documentos revelan la existencia de nueve empréstitos para la década de 1810 y dos más en el decenio siguiente, lo que ofrece un panorama aproximado de quiénes fueron los contribuyentes y los montos tributados. ${ }^{49}$

El primer empréstito solicitado data de 1813, año en que las autoridades del Cabildo realizaron un censo del capital existente en la ciudad. ${ }^{50}$ Esta medida tenía

Luis integró la primera Compañía de Comerciante con tan sólo catorce años. AHT, sección Administrativa, 1810 , fs. 33-44, y 1811, fs. 13-14.

${ }^{49}$ Las fuentes revelan el monto solicitado, las cantidades aportadas y quiénes fueron los contribuyentes. Asimismo, en 1816 la mayoría de los empréstitos se destinó al funcionamiento del Congreso Constituyente de ese mismo año efectuado en la provincia y que proclamó la independencia de las Provincias Unidas del Río de la Plata.

${ }^{50}$ AHT, sección Administrativa, 1813, f. 482. 
la finalidad de establecer una contribución para el sostenimiento del ejército y el monto de la misma varió de acuerdo con el capital que poseía cada individuo. En esta ocasión, Manuel Posse era el comerciante más acaudalado de la ciudad con un patrimonio estimado en 60000 pesos de acuerdo con lo declarado, por lo que aportó 1125 pesos que fue el monto más elevado. ${ }^{51}$ El único hijo que aparece censado fue José Víctor con una fortuna estimada en 7000 pesos, motivo por el cual tributó con 475 (véase anexo, cuadro 5). En este caso específico se evidencia que este integrante del clan Posse se sitúa entre los comerciantes de menor patrimonio en la ciudad. Sin embargo, al contrastar esta información con el capital que poseía al momento de su muerte -35091 pesos en 1852 - se deduce que era un comerciante en franco ascenso en el contexto local. ${ }^{52}$

En la sección Administrativa del Archivo Histórico de Tucumán se registró la restitución de un empréstito a los comerciantes de la ciudad para el mismo año. ${ }^{53}$ En esta ocasión Manuel Posse recibió 1125 pesos por concepto de devolución por una contribución previamente realizada a las autoridades locales. Sin embargo, si se analiza con mayor detenimiento este documento se observa que Posse fue quien percibió la suma más importante de acuerdo con el aporte que

${ }^{51}$ Los 60000 pesos no eran la cantidad de monetario que poseía Posse en su poder al momento del censo, sino una estimación de todos los recursos materiales de los que era propietario; entre ellos, propiedades, existencias en su almacén, dinero en efectivo, etcétera.

${ }^{52}$ Archivo de la Provincia (en adelante AP), sección Judicial Civil, serie A, caja 91, exp. 1852, fs. 1-30.

${ }^{53}$ AHT, sección Administrativa, 1813, f. 280. efectuó (véase anexo, cuadro 3). De las once personas a quienes se les restituyó el dinero aportado, sólo uno es tucumano, dos son afincados pero de origen peninsular-Posse y Alberdi-y el resto estaban identificados como españoles.

En 1815, el teniente gobernador Bernabé Araóz solicitó un nuevo empréstito por 10290 pesos con cargo de devolución en la capital de Buenos Aires mediante los libramientos que se franquearían a los interesados. ${ }^{54}$ Las sumas aportadas variaron entre 1000 pesos las mayores, y 50 pesos las menores. Sin embargo, si se observa el dinero aportado por la familia Posse en 1815 los montos contribuidos fluctuaron entre 100 y 350 pesos (véase gráfica 4). ${ }^{55}$

A partir de esta gráfica, ¿se puede inferir que los descendientes de Manuel Posse se situaban en una posición de franco ascenso económico en el contexto local? ¿Qué relación existió entre la mayor cantidad de monetario tributado con la ocupación de cargos en el Cabildo? De acuerdo con las fuentes analizadas, no es posible responder a estas interrogantes por dos motivos. Por una parte, este fue el primer empréstito en el que participaron todos los hijos del peninsular -con anterioridad sólo contribuyó José Víctor Posse-, hecho que no permite inferir con precisión la posición económica de los mismos en el contexto local debido a que se desconoce por qué fueron exceptuados del empréstito de $1813 .{ }^{56}$ En todo caso, si sólo se ana-

${ }^{54}$ Ibid., 1815, f. 15.

${ }^{55}$ Los hijos de Manuel Posse aportaron las siguientes sumas: José Víctor 350 pesos; Simón 300 pesos; Francisco 200 pesos, Vicente 100 pesos y Luis 100 pesos.

${ }^{56}$ En 1813 las autoridades del Cabildo solicitaron un empréstito de 12000 pesos y en esta ocasión 
Gráfica 4. Montos y cantidad de individuos que tributaron en el empréstito de 1815

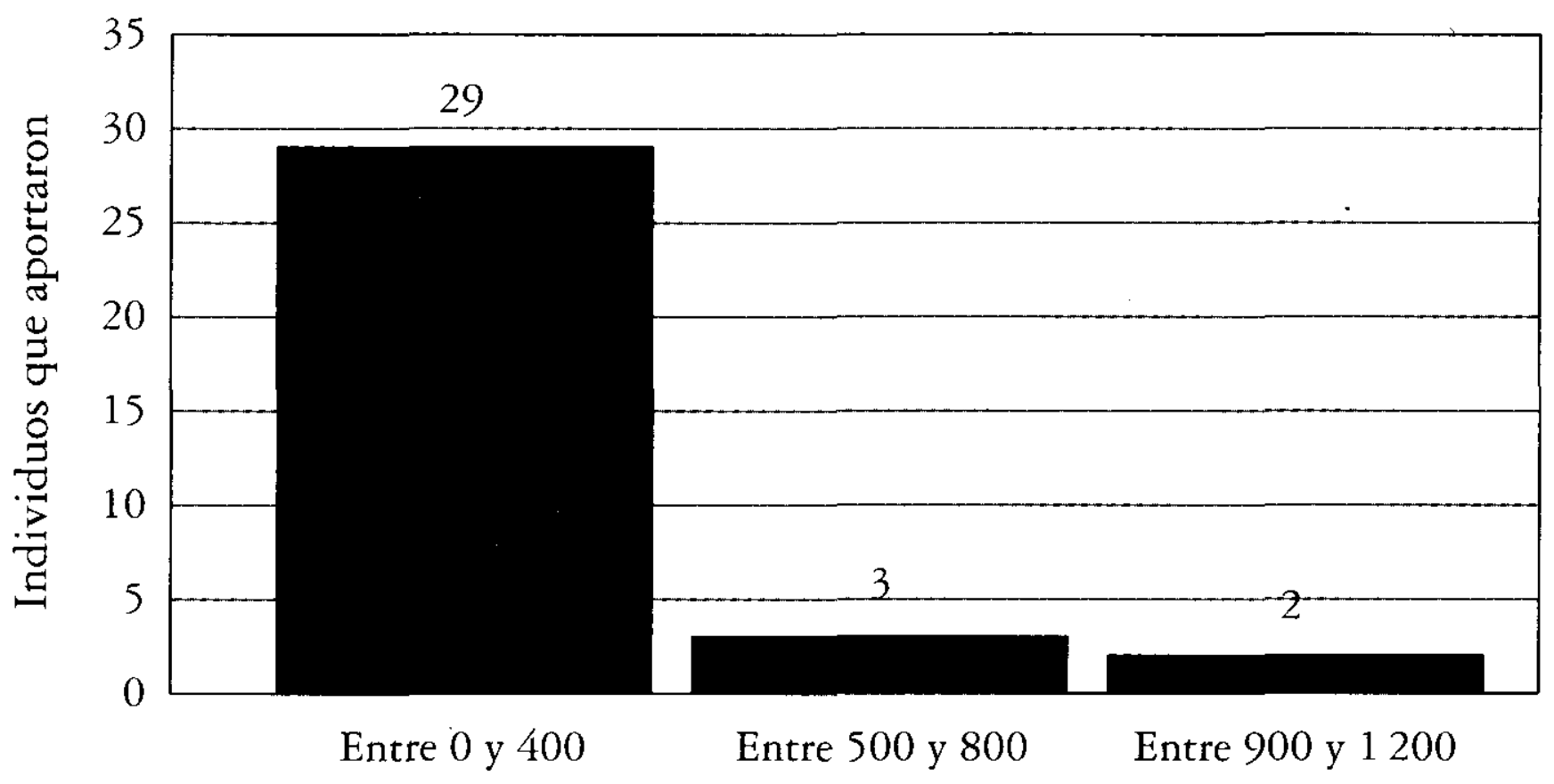

Montos en pesos aportados

Fuente: AHT, sección Administrativa, 1815, f. 15.

liza esta contribución se puede inferir que los descendientes de Posse se encuentran en el grupo de pequeños comerciantes, debido al monto contribuido. Por otra parte, no fue posible establecer ningún vínculo entre la suma tributada y el posicionamiento de los Posse en el Cabildo debido a que en 1815 sólo Francisco Posse participó en este ámbito como caballero síndico procurador de la ciudad. ${ }^{57}$

Ese mismo año, Manuel Posse solicitó el pago de 3000 pesos que aportó en calidad de empréstito al Cabildo. Esto ocasionó - de acuerdo con Leoni Pinto- una reacción por parte de las autoridades locales:

los recursos materiales de José Víctor Posse entre propiedades y existencia en su almacén eran de 7000 pesos, por lo que contribuyó con 131 pesos.

${ }^{57}$ Centro de Estudios Genealógicos de Tucumán, Boletín, núm. 5, 2007, p. 24.
Quienes consideran que Posse debe ser castigado para servir de ejemplo a otros que se valieron de iguales y maliciosas acechanzas, por tratar de aniquilar y detener sin suceso los progresos de sus benefactores [...] Posse pide el reintegro de los 3000 pesos cuando no le hacen falta y cuando esta capital se halla sumergida en un abismo de penas porque a pesar de sus esfuerzos patrióticos, acaso sin iguales, no puede socorrer a los valientes inválidos, viudas y ausentes de los que sostienen el campo de Marte. ${ }^{58}$

Esta situación revela una marcada tendencia de aminorar paulatinamente la participación de los peninsulares en los ámbitos políticos. La elección de Bernabé Araóz como gobernador propietario de la provincia -con el apoyo del jefe del ejército- debi-

${ }^{58}$ Leoni, Tucumán, 2008, p. 43. 
litó aún más la situación de los españoles peninsulares a quienes se acusó en diversas ocasiones de falta de patriotismo. ${ }^{59}$

En 1816, el diputado de Comercio requirió cuatro empréstitos forzosos con la finalidad de solventar los gastos del soberano Congreso que se realizaría en la ciudad de San Miguel de Tucumán. Manuel Posse no aparece en la lista de los contribuyentes, a pesar de los innumerables recursos materiales que poseía. ${ }^{60}$ Sus des-

${ }^{59}$ Bernabé Araóz era un militar de carrera perteneciente a una de las familias más prestigiosas del medio local. De acuerdo con Iramain: "La familia Araóz se conformó desde tiempos tempranos como una de las pioneras de la conquista y colonización de la región. Tuvo la capacidad de adaptarse a los cambios y transformaciones de la época haciendo uso no sólo de estrategias familiares, sino también de otras extrafamiliares. La diversificación de estas estrategias debe ser tenida en cuenta ya que puede explicar el papel que desempeñó no sólo la familia Araóz, sino el conjunto de las familias más importantes de la sociedad tucumana durante el proceso de independencia y la conformación de la provincia a comienzos de la década de los veinte [... L La guerra que desata el proceso de independencia les permitió a los miembros de la familia Araóz desempeñar un papel mucho más importante, ya que, como Bernabé, fueron capitanes de milicias, dieron préstamos, participaron en las expediciones al Alto Perú, etc. La batalla de Tucumán en 1812 vuelve a poner en el centro de la escena a los integrantes de este clan, en cuyos sucesos la historiografía clásica ha puesto mucho acento, y la carrera culmina cuando en 1814 Bernabé Araóz es nombrado primero teniente gobernador, y luego como gobernador intendente de Tucumán. Representante no sólo de su familia y de su persona, sino de toda la elite tucumana, la gesta de Bernabé en el proceso revolucionario le valió a la ciudad contar con un diputado extra en asamblea del año 1813." Iramain, "Proceso", 2005, pp. 104-105 y 110.

${ }^{60}$ No existen datos en las fuentes primarias que puedan aportar información de cuáles fueron los moti- cendientes tributan, aportando cada uno de ellos, diferentes montos: José Víctor (130 pesos), Vicente ( 75 pesos), Simón (70 pesos), Luis (65 pesos) y Francisco (30 pesos) (véase anexo, cuadro 5). En el caso de este último, las autoridades realizan una excepción con el monto que debía tributar por "las muchas contribuciones y empréstitos que ha sufrido". ${ }^{61}$ Los montos contribuidos en esta ocasión fueron menores que lo aportado un año antes. Esta situación sugiere que la suma impuesta en 1815 fue establecida de acuerdo con el criterio del diputado de Comercio. En este sentido, la nueva reglamentación favoreció a los hijos de Posse, quienes contribuyeron con cantidades menores.

En 1819 se solicitaron tres empréstitos forzosos. ${ }^{62}$ Manuel Posse contribuyó con un total de 1890 pesos, mientras que sus hijos aportaron las siguientes sumas: José Víctor 580, Luis 279, Vicente 140 y Simón 139. Se observa un aumento sustancial en la cantidad de monetario contribuido, a diferencia de 1816 en donde la suma más importante se asemeja al monto menor contribuido para 1819 que fue de 130 pesos (véase anexo, cuadro 5). Sin embargo, este incremento en el dinero

vos por los que Manuel Posse no contribuye en esta ocasión.

${ }^{61}$ A partir de 1816 se estableció el sistema de prorrateo que fijaba el monto de las contribuciones con base en las fortunas personales. AHT, sección Administrativa, 1816, fs. 225-226.

${ }^{62} \mathrm{La}$ diferencia entre el forzoso y los voluntarios residió en que, en el caso del primero, se estipuló de antemano la suma de 20000 pesos, mientras que en los segundos se pidió el monetario que se podía reunir. Asimismo, en el caso de estos últimos, uno de ellos fue dirigido exclusivamente hacia el sector de españoles peninsulares como muestra de lealtad y patriotismo. Ibid., 1819, f. 225 . 
cedido en estos empréstitos no se encuentra vinculado con una mayor participación de los integrantes de esta familia en el Cabildo de la ciudad. Sólo José Víctor Posse participa como miembro del $\mathrm{Ca}$ bildo cumpliendo funciones de alcalde ordinario de segundo voto en $1819 .{ }^{63}$ En todo caso, se interpreta que la posición económica de los hijos del peninsular había mejorado, hecho por el cual se los obligaba a tributar montos mayores, si se toma en cuenta que las sumas impuestas se ajustaban a una estimación de los recursos materiales que poseían.

Al finalizar la década de 1810, una característica sobresaliente fue la recurrente necesidad monetaria por parte de las autoridades del Cabildo para sostener el proceso revolucionario. En el decenio siguiente la realidad fue otra, como se verá a continuación.

\section{EMPRÉSTITOS EN EL TRANSCURSO DE LA DÉCADA DE 1820}

En el decenio de 1820, las autoridades del Cabildo de la ciudad solicitaron tres empréstitos para gastos de la guerra. En 1821 , el monto tributado fue de 8711 pesos, pero en este no contribuyó ninguno de los integrantes de la familia Posse. ${ }^{64}$

En 1823 se pidieron otros dos empréstitos. En el primero el monto total recaudado fue de 1499 pesos, donde tributaron los integrantes del clan familiar con diversos montos: Manuel Posse, padre, con 90 pesos; José Víctor, 90; Luis, 500, y Vicente

${ }^{63}$ Centro de Estudios Genealógicos de Tucumán, Boletín, núm. 5, 2007, p. 63.

${ }^{64}$ AHT, sección Administrativa, 1821, fs. 14, 224-225. con $50 .{ }^{65}$ En el segundo, el dinero recolectado asciende a 4829 pesos, donde los Posse contribuyeron de la siguiente forma: Manuel con 50 pesos; José Víctor, 30, Vicente, 40 , y Luis con $300 .^{66}$

En esta ocasión quien más contribuyó fue Luis Posse quien aportó 800 pesos entre las dos aportaciones, a diferencia de su padre que sólo tributó con 140 y sus hermanos que las dos veces no superaron los 120 pesos. Tampoco, en esta ocasión, la cantidad aportada por Luis tiene alguna vinculación con su desempeño como funcionario público.

Sin embargo, se piensa que el dinero entregado por Luis refleja una buena situación económica debido a que contribuyó con 800 pesos, y el monto se establecía de acuerdo con un prorrateo efectuado por el diputado de Comercio sobre el capital que poseían los comerciantes.

En resumen, el análisis de las contribuciones que les fueron impuestas a los vecinos de la ciudad de San Miguel de Tucumán -para el sostenimiento de la guerra- aporta un panorama que contrapone la situación de Manuel Posse con la de sus hijos. Por una parte, el iniciador del clan familiar en Tucumán, en el transcurso del proceso revolucionario, era un comerciante consolidado en la plaza local con una fortuna considerable, al igual que otros españoles peninsulares que se dedicaban a las actividades mercantiles, hecho que ocasionó la imposición de una serie de empréstitos. En la primera década revolucionaria, esta necesidad monetaria generó una erogación de 3015 pesos para el peninsular, quien contribuyó en cuatro de nueve empréstitos solicitados. Si se

\footnotetext{
${ }^{65}$ Ibid., 1823, fs. 123-124.

${ }^{66}$ Ibid., fs. 125-126.
} 
toma en cuenta que en 1813 la estimación de su patrimonio -de acuerdo con el censo efectuado por las autoridades del Cabildo- era de 60000 pesos, el dinero aportado en diferentes momentos - no en años sucesivos- no afectó su posición económica. Además, a partir de 1816 los montos contribuidos se establecieron de acuerdo con las fortunas personales $\mathrm{y}$, a pesar de ello, Posse no fue el que más contribuyó. Si bien es cierto que al momento de su muerte su capital era de 30887 pesos, esto estuvo relacionado con adelantos de herencia a sus hijos para que instalaran sus comercios en la ciudad.

Un hecho que incidió negativamente en la figura de Posse fue la acusación que las autoridades del Cabildo efectuaron en contra del peninsular por falta de patriotismo. Sin embargo, esto no afectó su participación pública debido a que no ocupaba un cargo desde 1804 cuando fue elegido alcalde ordinario de primer voto. Pra 1823 el peninsular retomó la función pública cuando fue elegido síndico procurador general. Este hecho anula cualquier posibilidad de articular -en el caso de Manuel Posse- poder político con poder económico. El peninsular mantuvo su capital económico pero se mantuvo en el ostracismo político en el marco del nuevo escenario planteado por el proceso revolucionario.

Los hijos de Manuel contribuyeron a la causa revolucionaria con montos menores. Esto indicaría una situación económica menos favorable debido a que el tributo se fijaba en relación con el capital que cada individuo poseía al momento de solicitarse la contribución (véase anexo, cuadro 5).

En la década de 1820 los pedidos de contribuciones -por parte de las autori- dades- indican dos situaciones. Por un lado, que el aporte por parte de Manuel Posse es menor en todas las ocasiones, lo que estaría reflejando un reparto más equitativo de las cargas en todos los sectores de la ciudad y no en uno específico. Por otro, los montos aportados por sus hijos son cada vez mayores, lo que revelaría un incremento en el patrimonio económico de cada uno de ellos (véase anexo, cuadro 5). En este sentido, los hijos de Posse capitalizaron esta situación económica favorable con la implementación de estrategias de reproducción social -mediante uniones matrimoniales- que los vincularon con prestigiosas familias de la elite local.

\section{ESTRATEGIAS DE REPRODUCCIÓN SOCIAL. \\ LOS ENLACES MATRIMONIALES DE LA PRIMERA GENERACIÓN DEL CLAN POSSE}

En este apartado se analizarán las uniones matrimoniales de los descendientes de Manuel Posse como estrategia de integración de capitales a la sociedad posrevolucionaria. En este sentido, un elemento insoslayable y estrechamente vinculado con la supervivencia de la elite esta relacionado con la implementación de adecuadas estrategias de reproducción social que tienen el propósito de conservar o aumentar el capital simbólico y económico de los clanes familiares. Sin embargo, la ejecución de estas estrategias no se encuentra disociada de las prácticas económicas que inciden directamente en la elección de ciertas familias y no de otras, para la constitución de una sólida red de parentesco.

Uno de los primeros antecedentes -en el caso específico de la producción historiográfica argentina- es el trabajo de Tulio Halperin Donghi, quien en 1970 
se percató de la existencia de un grupo de familias -en el contexto del Río de la Plata- que provenían de la colonia y sobrevivieron al proceso revolucionario. ${ }^{67}$ Las distintas alternativas que sortearon durante la independencia fortalecieron su red de relaciones y posibilitaron la consolidación política, económica y social de estas familias que dominaron el escenario pampeano a partir de 1830 . A partir de esta tesis, las diversas investigaciones abordaron distintas problemáticas relacionadas con la constitución de los clanes familiares en el contexto prerrevolucionario y posindependiente en las últimas décadas del siglo XX. ${ }^{68}$ Las contribuciones de estos investigadores resultaron sustanciales al momento de analizar la constitución de la familia Posse, debido a que aportaron una serie de sugerencias que contribuyeron para interpretar la lógica de parentesco utilizada.

Asimismo, el análisis de las contribuciones monetarias para la causa revolucionaria -realizado en la primera parte de esta investigación-, permitió una estimación respecto de cuáles eran las familias de mayor capital monetario en el ámbito local. Esta información resultó relevante al momento de reconstruir el entretejido parental de los Posse debido a que algunos

${ }^{67}$ Halperin, Proyecto, 1980.

${ }^{68} \mathrm{La}$ producción historiográfica vinculada a esta temática es sumamente amplia para el caso de Argentina. Véanse Bragoni, Hijos, 1999; Garavaglia, "Patrones", 1999; Hora, Terratenientes, 2002; Moutoukias, "Familia", 2000, y Moreno, Historia, 2004. Para el caso específico de Tucumán, los sugerentes aportes de Cristina López y Ana María Bascary iluminaron los aspectos centrales de la lógica implementada por las familias de la elite para su reproducción social, véanse Bascary, Familia, 1999, y López, Dueños, 2003. de los clanes familiares de elevada fortuna que se citan en las fuentes integraron la red de parentesco de la familia objeto de estudio.

Respecto al caso específico de los Posse, los descendientes del peninsular se unieron en matrimonio con integrantes de prestigiosas familias del medio local, de la ciudad de Santiago del Estero y de Buenos Aires, vinculadas a las actividades comerciales (véase anexo, figura 1). En cierto sentido, la constitución de estos enlaces se halló en estrecha vinculación con dos aspectos centrales que rigieron la lógica relacional. Por una parte, los hijos pusieron en práctica una estrategia que resultó exitosa para el caso de su padre. Por otra, las nuevas uniones matrimoniales reformularon los vínculos económicos previamente establecidos por su padre y por su tío -Gerardo Posse-, quien residía en Buenos Aires.

\section{LOS ENLACES MATRIMONIALES \\ DE LA PRIMERA GENERACIÓN}

José Víctor Posse contrajo matrimonio con Tomasa Pereira y Araóz, hija del prominente español Manuel Antonio Pereira quien firmó, junto a Manuel Posse, la declaratoria de la conformación de la Junta Provisoria. ${ }^{69}$ Su madre era Magdalena Aranguren Araóz, prima del general La Madrid - uno de los líderes del movimiento unitario de la Liga del Interiory sobrina de Bernabé Araóz, presidente fundador de la república del Tucumán entre fines de 1819 y principios de $1821 .^{70}$

\footnotetext{
${ }^{69}$ Documentos, 1939-1940, vol. I, p. 42.

${ }^{70}$ Granillo, Provincia, 1947, p. 98.
} 
La consumación de este enlace vinculó a José Víctor con dos familias representativas del ámbito local, como los Pereira y los Araóz; estos últimos propietarios de numerosas extensiones de tierras en el distrito de Monteros. De acuerdo con Groussac "eran casi como señores feudales en esas comarcas". ${ }^{71}$ En el aspecto político ambas familias participaban activamente en el Cabildo de la ciudad desde la segunda mitad del siglo XVIII.

En el caso específico de los Araóz, Bernabé fue en dos ocasiones gobernador propietario entre 1814-1817 y 1819-1821, mientras que Pereira participó activamente en el Cabildo hasta $1810 .^{72} \mathrm{La}$ elección de José Víctor como jefe del ejecutivo en forma provisional en 1822 no sólo estuvo relacionada con el desempeño como funcionario, sino también con el parentesco tan cercano con los Araóz. Sin embargo, este enlace no sólo benefició a José Víctor sino también a los Pereira, debido a que Tomasa se unió en matrimonio con un comerciante en franco ascenso con una fortuna de 7000 pesos para el año de $1813 .{ }^{73}$

Vicente Posse se casó con Sabina Talavera Olivera en la iglesia matriz de la ciudad de Santiago del Estero. ${ }^{74}$ Sabina era hija de José de Talavera, destacado comerciante y militar de extensa carrera que participó en la reconquista de Buenos Aires de 1806, quien obtuvo el grado de coronel y fue hermano de la prestigiosa Tercera Orden de la Penitencia en San-

${ }^{71}$ Groussac, Ensayo, 1981, p. 182.

${ }^{72}$ Documentos, 1939-1940, vol. I, p. 42.

${ }^{73}$ AHT, sección Administrativa, 1813, f. 351.

${ }^{74}$ Archivo de la Catedral de Santiago del Estero (ACSE), Matrimonios I, sección Matrimonios entre españoles, $2^{\circ}$ parte, f. 3 . tiago del Estero. ${ }^{75}$ Este enlace resultó una estrategia implementada por ambas familias para iniciar el vínculo comercial, hecho que posibilitó a Vicente relacionarse con otras familias de Santiago - por medio de su suegro- con las que concretó nuevos vínculos mercantiles. ${ }^{76}$

Simón Posse contrajo matrimonio en 1810 con su prima porteña Josefa Insúa y Collins, hija del comerciante Tomás Insúa a quien Manuel Posse exportaba suelas desde Tucumán. El hermano de Manuel - Gerardo- se casó con la hermana de Tomás -María Joaquina Insúa y Collins- en la ciudad de Buenos Aires a fines del siglo XVIII. ${ }^{77}$ El enlace de Simón fortaleció los lazos comerciales y parentales con sus familiares porteños. Francisco Posse reafirmó nuevamente este vínculo al casarse en la ciudad de Buenos Aires con su prima Rudencia Insúa y Collins, hermana de la esposa de Simón. ${ }^{78}$

Luis Posse, a diferencia de sus otros hermanos, contrajo matrimonio con Isabel Bores, hija legítima del español Francisco Bores y Carmen Velarde residentes en la ciudad de San Miguel de Tucumán. Bores era uno de los comerciantes más destacados de la ciudad, exportaba a Buenos Aires suelas, cueros, arroz, quesos, entre otros tantos productos, y fue uno de los que aportó mayores avances a la producción tabacalera en Tucumán. ${ }^{79}$ Su mujer era

${ }^{75}$ Centro de Estudios Genealógicos de Tucumán, Boletín, núm. 3, 2003 , p. 7.

${ }^{76}$ Esta es una hipótesis a confirmar a partir del análisis de las guías de comercio de importación y de exportación del AHT.

${ }_{77}$ Posse, Posse, 1996, p. 170.

78 Ibid., p. 175.

${ }^{79}$ En 1813 Francisco Bores poseía una fortuna estimada en 16000 pesos. AHT, sección Administrativa, 1813 , f. 351 . 
hermana de José Velarde, uno de los comerciantes más prominentes de San Miguel en 1813 con una fortuna calculada en 35000 pesos. ${ }^{80}$

Felipe Posse, el menor de los hijos de Manuel, fue el primero de los descendientes que contrajo matrimonio con una sobrina carnal, Rafaela Posse Insúa (hija de Simón). ${ }^{81}$ Rafaela quedó huérfana a corta edad quedándose al cuidado de su tío José Víctor. El casamiento de Felipe con su sobrina se interpretó como una estrategia para resguardar el patrimonio familiar. Este enlace fue el primero en el entorno intrafamiliar y a partir del mismo esta práctica fue recurrente en el transcurso de las generaciones.

La única hija de don Manuel -María del Rosario- se casó con Roque Pondal y Blanco. ${ }^{82}$ Este era originario de la zona de Camariñas (La Coruña, España) y durante los primeros años del siglo XIX radicó en Tucumán, donde desarrolló diversas transacciones comerciales. ${ }^{83}$ Fue procurador general (1810), regidor decano (1821), alcalde ordinario de segundo voto (1822), juez de primera nominación en lo civil (1826) y diputado de la Sala de Representantes (1829-1831). ${ }^{84}$ El enlace matrimonial entre Roque Pondal y María del Rosario benefició a ambos cónyuges de

${ }^{80}$ Ibid., f. 351.

${ }^{81}$ Posse, Posse, 1996, p. 47.

${ }^{82}$ Centro de Estudios Genealógicos de Tucumán, Boletín, núm. 4, 2004, p. 63.

${ }^{83}$ Las transacciones comerciales resultaron fructíferas debido a que en 1813 contaba con una fortuna estimada en 7000 pesos, a los que sumó 5000 pesos que María del Rosario Posse recibió como legítima herencia.

${ }^{84}$ Centro de Estudios Genealógicos de Tucumán, Boletín, núm. 4, 2004, p. 63. diferente manera. Por un lado, en el caso del peninsular, se incrementó su patrimonio de manera sustancial debido a que su esposa aportó 6504 pesos de su legítima herencia, que incluía una quinta por el valor de 1060 pesos con todo lo edificado y plantado. ${ }^{85}$ El capital aportado por su esposa permitió su consolidación definitiva en el contexto local. Por otra parte, María del Rosario se unió en matrimonio con un ascendente comerciante, lo que aseguró su continuidad en la elite tucumana. Asimismo, Pondal no era ningún extraño para Manuel Posse ya que existía un vínculo comercial que se reforzó mediante una serie de préstamos previos al enlace matrimonial. ${ }^{86}$

En síntesis, es posible analizar las uniones matrimoniales de los descendientes de Manuel Posse desde diversas perspectivas. Una característica inherente a los enlaces es el marcado perfil endogámico de los mismos, debido a que todos los descendientes se unieron a familias de origen español y con las cuales existieron ciertos lazos de consanguinidad. Este comportamiento no resulta fortuito de acuerdo con Hernán Otero que sostiene que los españoles tienen un marcado comportamiento endogámico, característica inherente a las pautas migratorias de este grupo. ${ }^{87}$

Asimismo, esto se relaciona con las apreciaciones de Andrea González Ripolli que plantea los vínculos de solidaridad intraoceánicas entre inmigrantes peninsulares, lo que aportaría un elemento más para comprender el propósito de ciertas uniones matrimoniales, en este caso espe-

\footnotetext{
${ }^{85}$ AHT, sección Protocolos, serie A, año 1839, fs. $21-24 \mathrm{v}$.

${ }^{86}$ Ibid.

${ }^{87}$ Otero, "Visión", 1990.
} 
cífico la de Roque Pondal-peninsular del mismo pueblo de donde emigró Manuel Posse- con María del Rosario.

Del mismo modo, la tendencia a vincularse con familias que realizan las mismas actividades económicas fue tratada para el caso latinoamericano por diversos investigadores -Brading, Kicza, entre otros-, así como también para el caso tucumano-Bascary y López-; estos autores afirman que dichas estrategias de reproducción social estuvieron destinadas a fusionar la elite colonial con sectores más dinámicos -los comerciantes peninsulares- con el propósito de mantener la preponderancia económica y el prestigio social. $^{88}$

Otra perspectiva sugerente la aporta Zacarías Moutoukias, quien afirma que los vínculos de parentesco de las elites coloniales se transformaron en el núcleo de relaciones -verticales y horizontalesque activaron los circuitos comerciales. ${ }^{89}$ En este sentido, los enlaces matrimoniales de los Posse con familias dedicadas a las actividades comerciales no sólo insinúan una marcada tendencia a preservar un capital económico, sino también a consolidar los circuitos mercantiles en los que estos actores se desenvolvieron. Sin embargo, esta apreciación se expresa en forma de hipótesis todavía debido a que no se indagó con profundidad en las guías de comercio en el Archivo Histórico de Tucumán.

Recapitulando, las motivaciones que generaron las uniones matrimoniales de los descendientes de Manuel Posse estuvieron vinculadas con la necesidad de

${ }^{88}$ Brading, Mineros, 1975; Kicza, Empresarios, 1986; Bascary, Familia, 1999, y López, Dueños, 2003.

${ }^{89}$ Moutoukias, "Familia", 2000, pp. 45-64. constituir nuevas relaciones comerciales, fortalecer lazos mercantiles previamente establecidos por el fundador del clan con la familia Insúa y Collins -primos hermanos- y generar la construcción de redes de solidaridad en donde el origen étnico -todos hijos de españoles nacidos en Tucumán- primara en función de la articulación de una red de relaciones mercantiles y parentales.

En síntesis, los descendientes de Manuel Posse no implementaron ninguna estrategia económica para evitar las contribuciones voluntarias o forzosas implementadas por el Cabildo. En todo caso, el pedido del peninsular por la restitución de un empréstito no se considera una estrategia para evitar los empréstitos sino como una iniciativa de pedir la devolución de una suma de dinero que las autoridades del Cabildo acordaron reintegrar previamente. Estos pedidos fueron recurrentemente efectuados por los comerciantes -de acuerdo con Leoni Pinto- ante la precaria situación económica que vivían.

En todas las ocasiones que les fueron solicitados los empréstitos aportaron el capital que se les impuso, sólo hubo una excepción en el caso de Francisco Posse debido a los numerosos préstamos y contribuciones que se realizaron sobre su persona. $^{90}$

Una cuestión inherente al caso de José Víctor Posse es que si bien su capital en 1813 era de 7000 pesos, su situación es la de un comerciante en franco ascenso en el medio local si se comparan estos datos con el patrimonio que poseía al momento de su muerte. Por este motivo, a pesar de que

${ }^{90}$ AHT, sección Administrativa, 1816, fs. 225226. 
las contribuciones no aportan el caudal necesario de datos, se pueden inferir otras cuestiones a partir de su comparación directa con los testamentos de los integrantes de la familia objeto de estudio. ${ }^{91}$

En todo caso, la catalogación que se les dio de enemigos de la causa revolucionaria y de falta de patriotismo -hacia los españoles peninsulares- fue un recurso esgrimido frecuentemente por las autoridades patrióticas en diversas coyunturas. Más que un conflicto entre padre e hijos lo que se observa es la adaptación de los descendientes a la situación revolucionaria y la generación de nuevos vínculos en un nuevo escenario, proyectando las estrategias de configuración del poder económico y social de su padre en la década revolucionaria y los años posteriores.

\section{CONCLUSIONES}

Las preguntas iniciales planteadas en esta investigación nos guiaron para expresar el análisis de dos ejes específicos: los empréstitos y las uniones matrimoniales de los integrantes de la primera generación de la familia Posse. En este sentido, un elemento insoslayable que recorre gran parte del periodo seleccionado es el tema de la guerra, problemática directamente vinculada con el proceso revolucionario y la necesidad recurrente de obtener recursos para sostener al ejército. En este contexto, marcado por la inestabilidad, la familia Posse atravesó el decenio de 1810 consolidando su posición económica y su esta-

${ }^{91}$ En este sentido, Manuel Posse se transforma en una especie de banquero para sus hijos a quienes ayudó en la instalación de sus respectivos emprendimientos comerciales. tus social mediante las uniones matrimoniales efectuadas.

$\mathrm{El}$ análisis de las contribuciones o empréstitos se planteó como una fuente pertinente que permitiría una aproximación de la incidencia de estas tributaciones en el patrimonio de Manuel Posse y de sus hijos. Esta reflexión se encuentra directamente vinculada con el importante capital material de este comerciante peninsular que de acuerdo con las fuentes analizadas en 1813 era de 60000 pesos y con la estrecha vinculación entre los montos tributados y el capital que los contribuyentes poseían. Esta premisa se sustentó en el hecho de que el peso del sostenimiento de la guerra -en el caso de la ciudad- recayó en los comerciantes pero, sobre todo, en el sector de españoles peninsulares, poseedores de las mayores fortunas.

Sin embargo, a partir de los datos aportados por la sección Administrativa del Archivo Histórico de Tucumán, no fue posible percibir si las contribuciones afectaron directamente el patrimonio de los Posse. Este impedimento esta vinculado con el desconocimiento de cuál era el capital de los actores objeto de estudio al momento de que eran solicitadas las contribuciones. Esto se relaciona con la resistencia de algunos comerciantes a tributar, denuncia frecuente de las autoridades revolucionarias. A pesar de estas dificultades, si se atiende específicamente a las fuentes analizadas, se observa que si bien los montos aportados por Posse eran significativos, dichas erogaciones no afectaron su patrimonio a pesar de que al momento de su muerte su capital había disminuido en casi $50 \%$-de 60000 pesos bajó a 30143 . En todo caso, esta merma en el patrimonio de Posse estuvo vincu- 
lada con los adelantos de la herencia asignada a sus hijos.

El estudio de las prácticas matrimoniales generó la revisión de la producción historiográfica referida a la historia de familia y a las formas de reproducción social de la elite americana, aunque esto no significó un análisis pormenorizado de los ejes del debate. La función que cumplió el estudio de esta producción fue la comparación de las estrategias matrimoniales implementadas por los Posse y las similitudes con otras regiones del territorio americano. En el caso específico del clan objeto de estudio, lo que subyace fue que las familias que integraron el entretejido parental estaban vinculadas al comercio, actividad que desempeñaban los Posse.

En este sentido, las uniones matrimoniales cumplieron diferentes propósitos. En algunas ocasiones consolidaron vínculos comerciales previos, como fue el caso específico entre los Posse y los Insúa. De esta manera, se mantuvieron los lazos de parentesco que unían a estas dos familias desde que Gerardo Posse - hermano de Manuel- contrajo matrimonio con María Joaquina Insúa y Collins y que vinculaba la provincia de Tucumán con la ciudad de Buenos Aires. Asimismo, esto significó la inclusión de nuevos actores económicos, como fue el caso de Simón y de Francisco Posse, quienes al igual que su padre se dedicaban al comercio.

Los enlaces matrimoniales que se realizaron con integrantes de prestigiosas familias del medio tucumano tenían el propósito de consolidar la posición económica, social y política de los Posse en el contexto local. Estas familias -los Bores y los Pereira-, se dedicaban al comercio, por lo que se presupone que se incorporaron al circuito comercial de los Posse o viceversa. Esta premisa todavía se expresa en forma de hipótesis debido a que en este artículo no se indagaron las particularidades del entorno comercial de la familia objeto de estudio.

Sin embargo, el enlace matrimonial entre Roque Pondal y María del Rosario Posse cumplió un propósito diferente. Esta hipótesis se sustenta en el hecho de que Pondal pertenecía al mismo pueblo de donde era originario Manuel Posse. En este sentido, la formalización del vínculo matrimonial se debe analizar desde dos perspectivas. Por una parte, como una estrategia de inclusión social debido a que el peninsular se casó con una integrante de la elite local -María del Rosario Posse-, lo que le permitió transformarse en vecino de la ciudad y desempeñarse como funcionario público. Por otra, como un lazo de solidaridad entre connacionales que benefició a Pondal, quien era un comerciante en franco ascenso en el medio tucumano. Asimismo, esto significaría una continuidad en las prácticas matrimoniales endógenas debido a que las familias que se incorporan al entretejido social de los Posse eran de origen peninsular.

Una práctica que comienza con la primera generación de los Posse es el casamiento intrafamiliar. Es decir, las uniones matrimoniales entre parientes, y en este caso específico entre tío y sobrina-Felipe Posse y Rafaela Posse Insúa. Esta estrategia fue implementada de manera recurrente entre la elite americana, por lo que el caso de los Posse no resulta extraño. Del mismo modo, estos enlaces matrimoniales cumplían la función de evitar la dispersión del patrimonio. Lo que subyace de las prácticas matrimoniales estudiadas es la intención manifiesta de consolidar no sólo vínculos económicos sino familia- 
res, con el propósito de mantener el prestigio del clan familiar en el contexto local.

Una característica distintiva de las familias de la elite colonial era la tendencia a situarse en diferentes ámbitos públicos. Las referencias con respecto a ello son frecuentes en la historiografía debido a que la sucesión en los cargos resultó una práctica recurrente. En este sentido, las reformas borbónicas fueron un intento por parte de las autoridades de la metrópoli de evitar la continuidad de estas prácticas en el territorio colonial. El proceso revolucionario incidió en este proceso debido a que generó nuevas oportunidades a los americanos de incorporarse a estos espacios de poder. Esto fue aprovechado por los descendientes de Manuel Posse, quienes generaron nuevos vínculos que les permitieron insertarse en la sociedad posrevolucionaria.

Una preocupación central en esta investigación fue determinar si las familias que se incorporaron al entretejido parental de los Posse se hallaban vinculadas a un espacio de poder específico. En este caso, lo que subyace es un marcado interés por parte de este clan de relacionarse con familias que desempeñaban funciones en el Cabildo de la ciudad. En todo caso, esta estrategia estaba relacionada con la intención de los Posse de obtener protagonismo en el medio local, lo que se expresaría con la participación paulatina desde 1783. Sin embargo, esta estrategia se encuentra asociada a la reproducción social debido a que este clan se vincula con familias que se dedicaban al comercio, pero que poseían una fuerte impronta política.

En síntesis, el proceso revolucionario, y más que nada la guerra, fueron determinantes en el territorio tucumano. Por este motivo, las autoridades del Cabildo de la ciudad implementaron una serie de empréstitos para solventar los gastos ocasionados para el mantenimiento del ejército. Estas contribuciones recayeron en el sector de españoles peninsulares poseedores de las mayores fortunas, aunque esto no significó que el resto de los comerciantes tucumanos no aportaran para la causa revolucionaria. Sin embargo, las fuentes indagadas sólo permitieron observar el patrimonio de dos integrantes de la familia Posse, Manuel y su hijo José Víctor. A pesar de ello, resultó claro que los montos aportados tenían en la mayoría de los casos una correlación directa con el patrimonio poseído. Por este motivo, lo que subyace son dos situaciones contrapuestas: Manuel Posse consolidado en la plaza local mientras que sus hijos eran comerciantes en franco ascenso.

Asimismo, las uniones matrimoniales tuvieron la finalidad de consolidar el prestigio de los Posse en el contexto local y, sobre todo, dieron la posibilidad de generar nuevos espacios de participación política, que fueron perdidos por el fundador del clan dada su condición de español peninsular. 
Cuadro 1. Personas que más contribuyeron en la década de 1810

$\begin{array}{lllcc}\text { Nombre y apellido } & \text { Origen } & \text { Ocupación } & \begin{array}{c}\text { Cantidad } \\ \text { (en pesos) }\end{array} & \begin{array}{c}\text { Número } \\ \text { de veces }\end{array} \\ \text { Pedro Cayetano Rodríguez } & \text { Español } & \text { Tendero } & 5802 & 9 \\ \text { José Ignacio Garmendia } & \text { Español } & \text { Comerciante } & 1881 & 9 \\ \text { José Gramajo } & \text { Tucumano } & - & 1031 & 6 \\ \text { Manuel Méndez } & \text { Español } & \text { Comerciante } & 1914 & 6 \\ \text { Francisco Bores } & \text { Español } & \text { Comerciante } & 1031 & 5 \\ \text { José Víctor Posse } & \text { Tucumano } & \text { Comerciante } & 1191 & 7 \\ \text { Manuel Posse } & \text { Español } & \text { Afincado } & 3015 & 4 \\ \text { José Antonio Carmona } & \text { Tucumano } & \text { Pulpero } & 1021 & 6 \\ \text { Manuel Francisco Monteagudo } & \text { Tucumano } & \text { Comerciante } & 1268 & 2 \\ \text { Manuel Antonio Pereyra } & \text { Español } & - & 700 & 3 \\ \text { Roque Pondal } & \text { Español } & - & 2793 & 6 \\ \text { Pedro Alfeiran } & \text { Español } & \text { Tendero } & 4641 & 5 \\ \text { Domingo Antonio Insúa } & \text { Español } & - & 1227 & 5 \\ \text { Juan Ignacio Malde } & \text { Córdoba } & \text { Pulpero } & 1235 & 4 \\ \text { José María Orneta } & \text { Tucumano } & - & 1716 & 4 \\ \text { Pedro Castañeda } & - & - & 2000 & 3 \\ \text { Pedro José Ibaceta } & \text { Español } & - & 3170 & 3 \\ \text { Andrés Ugarriza } & \text { Español } & - & 2760 & 3\end{array}$

Fuente: Iramain, "Proceso", 2005, pp. 128-129.

Gráfica 1. Porcentaje de contribuciones de acuerdo con el origen étnico en la década de 1810

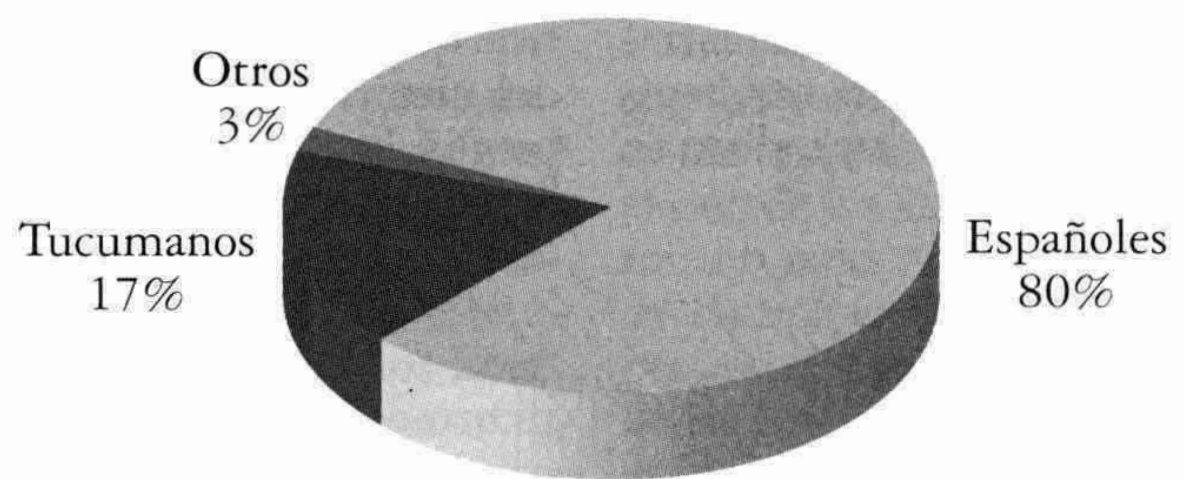

Fuente: Iramain, "Proceso”, 2005, pp. 128-129. 
Cuadro 2. Censo de capital existente en el gremio de comerciantes en 1813

Nombre

Manuel Posse

José Velarde

Francisco Monteagudo

Cayetano Rodríguez

José Ignacio Garmendia

Manuel Méndez

Francisco Bores

Manuel Martínez

José Alberca

Salvador Alberdi

Pedro José Medina

José Gramajo

José Víctor Posse

Ignacio Figueroa

José Manuel Silva

Esteban Galíndez

Roque Pondal

Félix Vico

José Gabriel Carmona

Cayetano Araóz

Bernardo Canibe

Borja Aguilar

Tomás Elliot

Pedro Chaneton

Pedro Patricio Zavalía

Lorenzo Domínguez

Saturnino Laspiur

Leonor Herrera

Gabriel Ríos

José Araóz

Pedro Velarde

Antonio Ferry

Juan Colombres

Sinforoso Bayo
Ocupación

Comerciante

Comerciante

$$
-
$$$$
\text { - }
$$

Comerciante

Comerciante

Comerciante

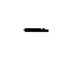

$-$

Afincado

Pulpero

Comerciante

Comerciante

E. correos

Comerciante

Comerciante

$$
-
$$$$
-
$$

Comerciante

$$
-
$$

Afincado

Jabonero

$$
-
$$

Pulpero

Comerciante

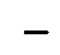

$-$

Hacienda

Comerciante

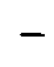

$-$

$-$
Capital (en pesos)

Monto tributado (en pesos)
60000

35000

25000

20000

20000

16000

16000

11000

10000

10000

8000

8000

7000

6000

6000

5000

5000

4000

- 4000

4000

4000

4000

4000

4000

4000

3000

3000

3000

3000

3000

2000

1000

1000

1000
1125

696

468

375

375

300

300

206

187

187

150

150

434

122

112

93

93

75

75

75

75

75

75

75

75

56

56

56

56

56

37

18

18

18

Fuente: AHT, sección Administrativa, 1813, f. 482. 
Cuadro 3. Restitución de un empréstito a los comerciante en 1813

Nombre
Salvador Alberdi
José Alverca
Francisco Bores
Ignacio Figueroa
José Ignacio Garmendia
Manuel Méndez
Francisco Monteagudo
Roque Pondal
Manuel Posse
Javier Rodríguez
José Velarde
Total

Capital de acuerdo con el censo de 1813 (en pesos)

Afincado

Español

Español

Europa

Español

Español

Tucumano

Español

Afincado

Europa

Europa
10000

10000

16000

6000

20000

16000

25000

5000

60000

$-$

$-$
Monto restituido

(en pesos)

187

187

375

112

375

300

368

93

1125

375

696

4163

Fuente: AHT, sección Administrativa, 1813, f. 280.

Cuadro 4. Sucesión de Manuel Posse (en pesos)

$\begin{array}{lrcc}\text { Nombre } & \text { Adeuda } & \text { Legítima berencia } & \text { Saldo a favor de la madre } \\ \text { Vicente Posse } & 7737 & 4497 & 2233 \\ \text { José V. Posse } & 7635 & 5000 & 1635 \\ \text { Simón Posse } & 7656 & 5504 & 2152 \\ \text { María del R. Posse } & - & 6504 & 1302 \\ \text { Francisco Posse } & 8686 & 5504 & 3181 \\ \text { Luis Posse } & - & 5504 & - \\ \text { Felipe Posse } & 6609 & 1105 & 1105\end{array}$

Fuente: AHT, sección Protocolos, serie A, 1839, f. 134v. 


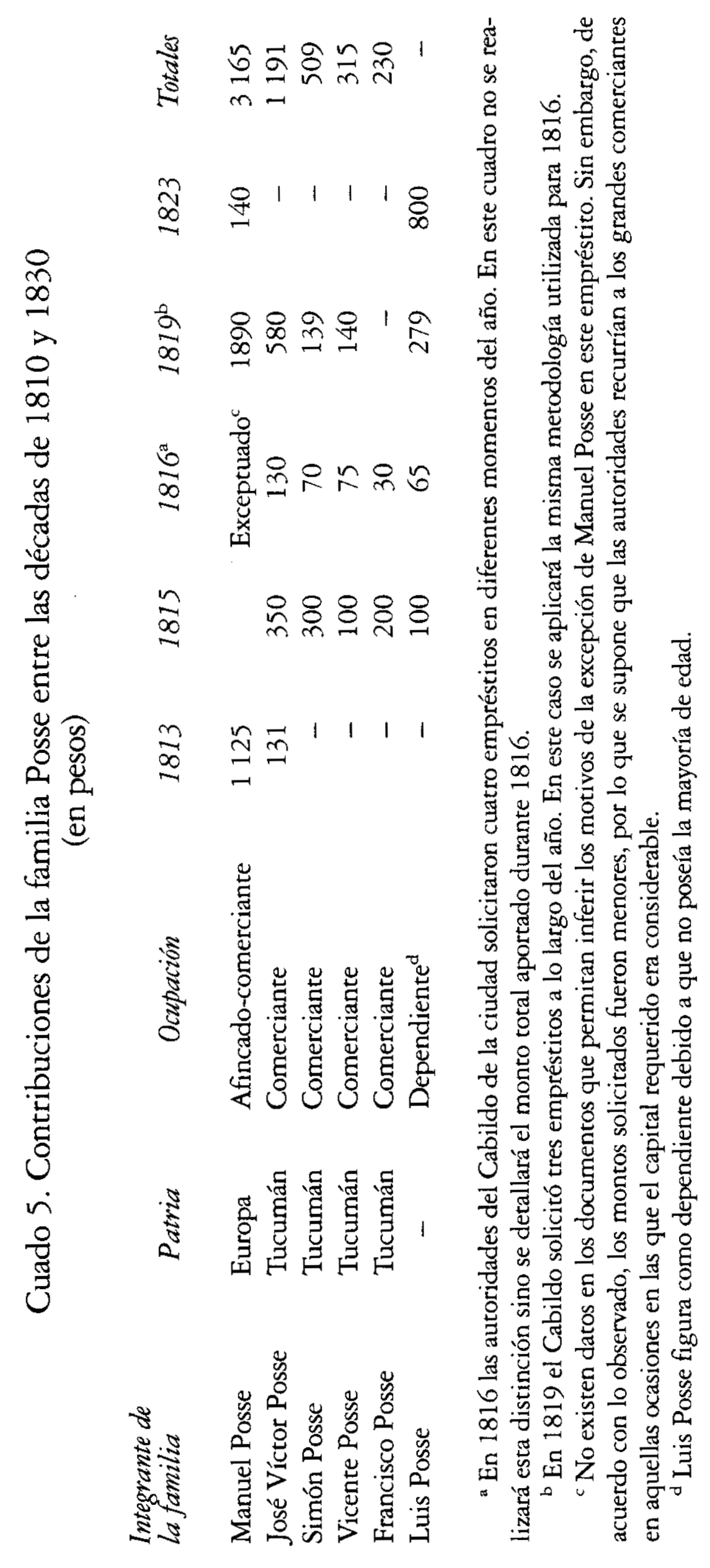


Figura 1. Uniones matrimoniales de la primera generación de los Posse

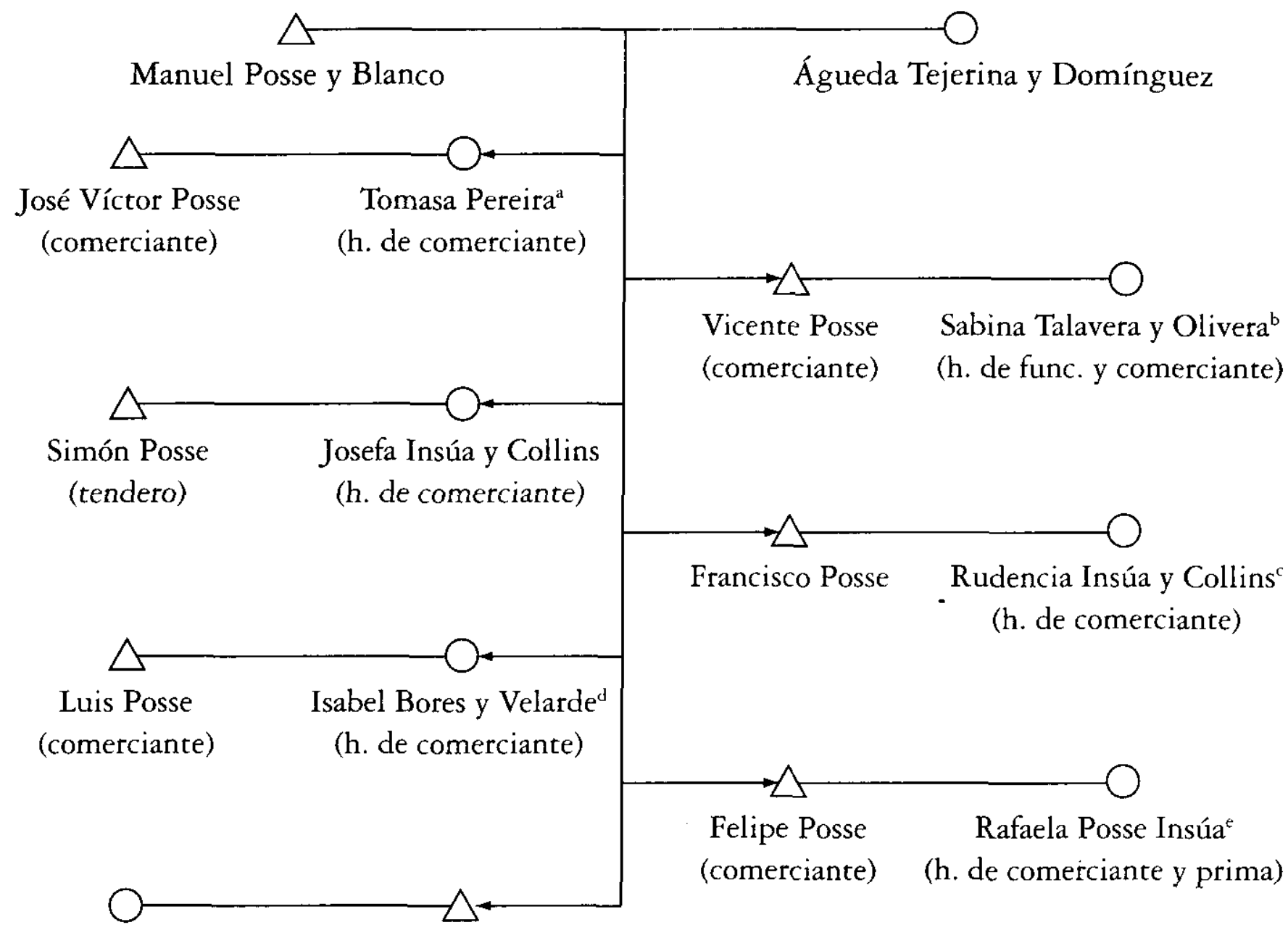

María del R. Posse Roque Pondal y Blanco

(h. de comerciante) (comerciante)

a Tomasa Pereira estaba emparentada con Bernabé Araóz (presidente de la ex república de Tucumán) y La Madrid (gobernador en Tucumán a fines de la década de 1820).

${ }^{\mathrm{b}}$ Func. = hija de funcionario de Cabildo en la ciudad de Santiago del Estero.

' Rudencia Insúa y Collins era hermana de Josefa Insúa y Collins, quien se casó con Simón Posse.

'Isabel Bores era hija de Francisco Bores, quien aportó su conocimiento para el fortalecimiento de la producción tabacalera en Tucumán y emparentado con la familia Velarde, importantes comerciantes locales.

' Rudencia Posse Insúa era hija de Simón Posse y de Josefa Insúa y Collins. 
FUENTES CONSULTADAS

Archivos

AHT Archivo Histórico de Tucumán.

ARG Archivo del Reino de Galicia.

AP Archivo de la Provincia.

ACSE Archivo de la Catedral de Santiago del Estero.

ACT Archivo de la Catedral de Tucumán.

APC Archivo Parroquial de Camariñas.

\section{Bibliografía}

-Balmori, Diana, Stuart F. Voss y Miles Wortman, Las alianzas de familia y la formación del país en América Latina, FCE, México, 1990.

-Bascary, Ana María, "Poder y familia en San Miguel de Tucumán a fines del periodo colonial. El caso de los Villafañe" en Actas del IV Encuentro de Latinoamericanistas españoles, Universidad de Salamanca, Salamanca, 1994. , Familia y vida cotidiana a fines de la colonia, Facultad de Filosofía y Letras-UPO, Tucumán, 1999.

-Burke, Peter, La revolución bistoriográfica francesa. La escuela de los Annales: 1929-1989, Gedisa, España, 1994.

-Brading, David, Mineros y comerciantes en el México borbónico (1763-1810), FCE, México, 1975.

-Bragoni, Beatriz, Los hijos de la revolución. Familia, negocios y poder en Mendoza en el siglo XIX, Taurus, Buenos Aires, 1999.

-Centro de Estudios Genealógicos de Tucumán, Boletín, núm. 3, 2003, Tucumán. , Boletín, núm. 4, 2004, Tucumán. , Boletín, núm. 5, 2007, Tucumán.

-Documentos tucumanos. Actas del Cabildo, pról. y notas de Manuel Lizondo Borda, Instituto de Historia, Lingüística y Folklore-Universidad Nacional de Tucumán, Tucumán, 1939-1940, 2 vols.
-García de Saltor, Irene, La construcción del espacio político. Tucumán en la primera mitad del siglo XIX, Facultad de Filosofía y Letras-UNT, Tucumán, 2003.

-Garavaglia, Juan Carlos, "Patrones de inversión y elite económica dominante: los empresarios rurales de la pampa bonaerense a mediados del siglo XIX" en Juan Carlos Garavaglia, Jorge Gelman y Blanca Zeberio (comps.), Expansión capitalista y transformaciones regionales. Relaciones sociales y empresas agrarias en la Argentina del siglo XIX, Tandil, Buenos Aires, 1999. , Jorge Gelman y Blanca Zeberio (comps.), Expansión capitalista y transformaciones regionales. Relaciones sociales y empresas agrarias en la Argentina del siglo XIX, Tandil, Buenos Aires, 1999.

-Gelman, Jorge, De mercanchifle a gran comerciante. Los caminos del ascenso en el Río de la Plata colonial, Universidad Internacional de Andalucía, Sevilla, 1996.

-Gil Montero, Raquel, "Guerras, hombres y ganados en la Puna de Jujuy. Comienzos del siglo XIX", Boletín del Instituto de Historia Argentina y Americana "Dr. Emilio Ravignani", núm. 25, 2004, Buenos Aires, pp. 9-36.

-Granillo, Arsenio, Provincia de Tucumán, Publicaciones de la Junta Conservadora del Archivo Histórico de Tucumán, Tucumán, 1947.

-Groussac, Paul, Ensayo histórico sobre Tucumán, Ediciones Fundación Banco Comercial del Norte, Tucumán, 1981.

-Halperin Donghi, Tulio, Proyecto y construcción de una nación, Biblioteca Ayacucho, Buenos Aires, 1980.

, Revolución y guerra. Formación de una elite dirigente en la argentina criolla, Siglo XXI, Buenos Aires, 1994.

-Herrera, Claudia, "Elites y poder en Argentina y España en la segunda mitad del siglo XIX", tesis doctoral, Universidad Complutense de Madrid, Madrid, 2003. 
, "Redes de parentesco, azúcar y poder.

La elite azucarera tucumana en la segunda mitad del siglo XIX", Entrepasados. Revista de Historia, núm. 31, 2007, Buenos Aires.

-Hora, Roy, Los terratenientes de la pampa Argentina. Una historia social y política 1860-1945, Ediciones Siglo XXI, Buenos Aires, 2002.

-Iramain, Pablo, "El proceso de independencia a través de las familias principales. Tucumán entre 1810-1820" en Irene García de Saltor y Cristina López (comps.), Representaciones, sociedad y poder. Tucumán en la primera mitad del siglo XIX, Facultad de Filosofía y Letras-UNT, Tucumán, 2005.

-Kicza, John, Empresarios coloniales, familias y negocios en la ciudad de México durante los Borbones, FCE, México, 1986.

-Laslett, Peter, "Introducción al estudio de la familia" en Cambridge Group for the History of Population and Social Structure, Cambridge, Londres, 1972.

-Leoni Pinto, Ramón, "Empréstito y comercio en Tucumán. Introducción a su estudio (1810-1825)" en Actas del Primer Congreso de Historia Argentina y Regional, ANH, Buenos Aires, 1973, pp. 165-177.

,Tucumán y la región del noroeste. Periodo 1810-1825, UNT, Tucumán, 2008.

-Lizondo Borda, Manuel, Historia de Tucumán, UNT, Tucumán, 1948.

-López de Albornoz, Cristina, "Tiempos de cambio: producción y comercio en Tucumán (1770-1820)", Revista Andes, núm. 13, 2002.

-López, Cristina, "Comercio de exportación de la jurisdicción de San Miguel de Tucumán: circuitos comerciales y especialización productiva (1785-1810)", Cuadernos de Contexto Andino, Consejo de Investigaciones Científicas y Técnicas de la Universidad Nacional de Tucumán, núm. 2, 1994.

, Los dueños de la tierra. Economía, sociedad y poder en Tucumán (1770-1820), Facultad de Filosofía y Letras-UNT, Tucumán, 2003.
"Redes de parentesco y poder en la frontera de Tucumán: la familia Alurralde" en Cristina López (comp.), Familia, parentesco y redes sociales, Facultad de Filosofía y Letras-UNT, Tucumán, 2004.

"Familias, negocios y revolución: la construcción de nuevas relaciones de poder en Tucumán (1770-1820)", VI Encuentro de Historia Regional Comparada, Siglos XVI a mediados del xIX, Universidad Nacional de Salta, 2004.

-Marchionni, Marcelo Daniel, "Una elite consolidada. El Cabildo de Salta en tiempos de cambios" en Sara Mata de López (comp.), Persistencias y cambios: Salta y el noroeste argentino. 1770-1840, Prohistoria \& Manuel Suárez, Rosario, 1999.

-Mata, Sara, "Costo económico y social en la guerra de independencia. Salta en la primera década revolucionaria”, Segundas Jornadas de Historia Económica, Montevideo, 1999.

-Moreno, José Luis, Historia de la familia en el Río de la Plata, Sudamericana, Buenos Aires, 2004.

-Moutoukias, Zacarías, "Familia patriarcal o redes sociales: balance de una imagen de la estratificación social", Anuario del IEHS, núm. 15, 2000, Buenos Aires.

-Nicolini, Esteban, "Circuitos comerciales en Tucumán entre 1825 y 1852 . Tensión entre el mercado del Pacífico y el del Atlántico", Data, revista del Instituto de Estudios Andinos y Amazónicos, núm. 2, 1992, La Paz, pp. 63-95. , Flujos de mercancías y dinero en Tucumán en la primera mitad del siglo XIX. Aproximación metodológica, Facultad de Filosofía y Letras-UNT, Tucumán, 1994.

, "El comercio en Tucumán 18101815: flujos de mercancías, dinero y balanzas comerciales", Población y Sociedad, Fundación Yocavil, núm. 2, 1994, Tucumán, pp. 47-79.

-Otero, Hernán, "Una visión crítica de la endogamia: reflexiones a partir de una reconstrucción de familias francesas (Tandil, 1850- 
1914)", Estudios Migratorios Latinoamericanos, año 5, núms. 15-16, agosto-diciembre de 1990, Buenos Aires, pp. 343-379.

-Posse, José María, Los Posse. El espiritu de un clan, Sudamericana, Buenos Aires, 1996.

-Schmit, Roberto, Ruina y resurrección en tiempos de guerra. Sociedad, economía y poder en el oriente entrerriano posrevolucionario, Prometeo, Buenos Aires, 2004.
-Socolow, Susan, Los mercaderes de Buenos Aires virreinal: familia y comercio, Ediciones La Flor, Buenos Aires, 1991.

-Tío Vallejo, Gabriela, Antiguo régimen y liberalismo en Tucumán, 1770-1830, Facultad de Filosofía y Letras-UNT, Tucumán, 2001 (Cuadernos de Humanitas). 